\title{
D-InSAR monitoring of ground deformation related to the dewatering of construction sites. A case study of Glòries Square, Barcelona
}

\author{
Joan Botey i Bassols ${ }^{\mathrm{a}, \mathrm{b},{ }^{*} \text {, Enric Vàzquez-Suñé }}{ }^{\mathrm{a}}$, Michele Crosetto ${ }^{\mathrm{c}}$, Anna Barra ${ }^{\mathrm{c}}$, Pierre Gerard $^{\mathrm{b}}$ \\ ${ }^{a}$ Institute of Environmental Assessment \& Water Research (IDAEA), CSIC, C. Jordi Girona 18-26, 08034 Barcelona, Spain \\ ${ }^{\mathrm{b}}$ Building, Architecture and Town Planning (BATir) department, Université libre de Bruxelles (ULB), Av. F. Roosevelt 50, CPI 194/02, 1050 Brussels, Belgium \\ ${ }^{\mathrm{c}}$ Centre Tecnolòic de Telecomunicacions de Catalunya (CTTC/CERCA), Division of Geomatics, Av. Gauss 7, 08860 Castelldefels, Barcelona, Spain
}

\section{A R T I C L E I N F O}

\section{Keywords:}

Differential interferometric SAR

Hydrogeology

Dewatering

Civil works

Ground deformation

Levelling

\begin{abstract}
A B S T R A C T
The aim of this paper is to demonstrate how the integration of differential interferometric synthetic aperture radar (D-InSAR) and levelling improves the monitoring of ground deformation phenomena, thereby enabling their complete understanding. The complementarity between D-InSAR and levelling is illustrated through a case study of the construction of a road tunnel beneath Glòries Square, Barcelona; D-InSAR is employed to continuously monitor the works, notably the dewatering of the site. This study focuses primarily on D-InSAR data obtained from the processing of Sentinel-1A data following a persistent scatterer interferometry procedure. The spatial distribution of the deformation and its temporal evolution are analysed with detailed hydrogeological and piezometric data. The magnitude of deformation is discussed using levelling data and an analytical estimation based on the hydromechanical parameters of the ground obtained from a pre-existing hydrogeological numerical model and pumping tests. The D-InSAR results are shown to be essential for identifying the origin of ground deformation and the constraints on its spread. Such observations at the construction site and district $(\sim 2 \mathrm{~km}$ radius) scales with sub-centimetric deformation are precious contributions of D-InSAR data, whereas levelling offers a more accurate quantification of the deformation, although this remains an open issue to be further investigated.
\end{abstract}

\section{Introduction}

The work of technicians and researchers who play a role in land management is both explicitly and implicitly guided by the concept of risk, which is the product of the probability of a certain phenomenon occurring and the damage that the phenomenon is capable of causing. Thus, the highest socioeconomic risks are usually concentrated in urban areas, whereas the highest environmental risks are found in areas of high ecological value. In urban areas, a common problem in risk management is the interactions between multiple agents acting on the environment. In such cases, detaching the contribution of each agent within the resulting global situation is often a complex yet necessary task for the responsible management authority (Bansal et al., 2013; Corominas et al., 2014; Flower et al., 2018; Svalova, 2018).

Risks in urban areas are notoriously high and complex to manage; unfortunately, these risks also become increasingly frequent over time. The natural evolution of a city itself makes space increasingly scarce. In the early stages of urban growth, when available space is still abundant, infrastructures are built on the surface for simplicity and economy. As space becomes occupied and the city becomes increasingly dense, infrastructures are buried to free up the progressively valuable space on the surface. At first, these facilities are buried near the surface, primarily for technical and economic convenience; however, as the available underground space decreases, it becomes necessary to work at greater depths (Eddies et al., 2020; Herce Vallejo and Magrinyà Torner, 2002; Duranton and Puga, 2014). Consequently, in dense urban environments, infrastructures are often built below the water table, which requires dewatering during their construction and potentially during their exploitation as well (Pujades et al., 2014b). Therefore, these operations become increasingly risky, inducing a variety of detrimental phenomena ranging from small magnitudes of settlement, which may or may not be differential depending on the geological context, to sinkholes and collapses (Clarke and Laefer, 2014; Cheng et al., 2020; Font-Capó et al., 2011; Font-Capó et al., 2015; Haack, 2010; Jurado et al., 2012; Pujades et al., 2012). In other words, the risks related to civil works in urban environments are increasing, and thus, administrations urgently need to

\footnotetext{
* Corresponding author at: Institute of Environmental Assessment \& Water Research (IDAEA), CSIC, C. Jordi Girona 18-26, 08034 Barcelona, Spain.

E-mail address: w.jbotey@gmail.com (J. Botey i Bassols).
} 
control and manage these risks (Clarke and Laefer, 2014; Eddies et al., 2020; Vàzquez-Suñé et al., 2005).

In this context, regarding soil deformation, the most common and well-established monitoring techniques, such as levelling, are highly accurate and reliable; however, being point-like techniques, these methods have a limited temporal but especially spatial capacity to describe deformation, making it difficult to obtain a complete view of the problem. Accordingly, differential interferometric synthetic aperture radar (D-InSAR) could be a very useful tool, as it is capable of detecting and measuring deformation with a high sampling density in both space and time without having to prioritise the spatial density over the extent of the monitored area or vice versa (Karila et al., 2013; Serrano-Juan et al., 2017).

D-InSAR comprises a family of radar techniques that measure the deformation of the ground surface. D-InSAR is economically competitive and able to measure deformation with a high spatial density at subcentimetre scale regardless of daylight and being little affected by the meteorology; moreover, these techniques are capable of automatically acquiring data (Galloway and Hoffmann, 2007; Rosen et al., 2000). In addition, satellite data -ground-based SAR (GB-SAR) also exists- can cover large areas (from hundreds to tens of thousands of square kilometres), new SAR images are available every few days (6 days for Sentinel-1) and a historical archive of imagery is available, allowing for retrospective studies (Carnec and Delacourt, 2000; Galloway and Hoffmann, 2007).

The D-InSAR working principle consists of measuring the difference in the wave phase between two radar images acquired at different times over the same area. This phase is related to the distance between the radar and the ground; more specifically, the change in the phase between two instants is directly related to the deformation of the ground surface. The complexity encountered when processing SAR data is that deformation is not the only factor that may alter the wave phase. Hence, processing consists of isolating the deformation from noise and the other contributions, such as the topographic, atmospheric and thermal expansion components (Crosetto et al., 2016; Wasowski and Bovenga, 2014).

Furthermore, analysing the D-InSAR performance is a complex issue. The large number of parameters involved in SAR data processing may lead to different D-InSAR results, even when working with the same SAR dataset (Wasowski and Bovenga, 2014). Several strategies exist to analyse the quality of D-InSAR results: using both ascending and descending data from the same sensor(s) for the same area and period; using data from different sensors for the same area and period; using the same dataset but different data processing schemes; and validating the results with non-D-InSAR data, such as global positioning satellite system (GNSS), levelling or extensometer data (see Wasowski and Bovenga, 2014, and references therein). Thus, the literature already contains studies in which D-InSAR performance has been analysed, notably regarding the spatial patterns of deformation and its temporal evolution (see, for instance, Cabral-Cano et al., 2008; Del Soldato et al., 2018; Galloway and Burbey, 2011; Galloway and Hoffmann, 2007; Lu and Danskin, 2001; Tomás et al., 2005). However, quantitative analyses of the D-InSAR accuracy and precision are less abundant. Some comparisons can be found between different D-InSAR datasets or with data from other point-like techniques such as levelling and GNSS data (in addition to some of the aforementioned works, see Mahmoudpour et al., 2016; Motagh et al., 2017; Perski et al., 2009; Yerro et al., 2014). Nevertheless, most of these studies were performed at the regional scale (areas larger than hundreds of square kilometres), while there are few cases involving quantitative comparisons between D-InSAR and levelling data at the local scale (i.e. at the construction-site scale, less than $10 \mathrm{~km}^{2}$ ). At such scales, few data are available for the clustered or aggregated analysis of contiguous point or pixel data -which minimise the weights of eventual residual errors in some pixels- and thus, the analysis must rely on single points; therefore, higher-quality D-InSAR data are needed, not only at the dataset level but also at the point level. Nevertheless, Karila et al.,
2013 conducted a comparison of the subsidence rates of building foundations obtained with both D-InSAR and levelling, and SerranoJuan et al., 2017 compared D-InSAR and levelling results in a case study of ground settlement associated with the dewatering of construction civil works in an urban area. Both cases show the potential of D-InSAR in urban areas at the building scale.

All the abovementioned works analysed and compared the performance of D-InSAR with that of other techniques. The aim of this paper is to highlight how the integrated use of levelling and D-InSAR in the monitoring of ground deformation allows their complementary strengths to be fully utilised, namely, the high accuracy and reliability of levelling and the broad extent and high spatial density of D-InSAR data. The results of this integration in a case study of the construction of a road tunnel beneath Glòries Square in Barcelona and the subsequent dewatering of the excavation highlight the difficulty of understanding the whole deformation phenomenon with point-like monitoring techniques. Here, D-InSAR is shown to be crucial in identifying the origin of the deformation and its controlling factors. Moreover, in this case, DInSAR is included in the continuous monitoring of works performed by the Construction Management (CM) office, thus confirming that this technique can be suitable for monitoring deformation phenomena not only at the local scale but also in such challenging and changing contexts as ongoing construction sites.

\section{Materials and methods}

\subsection{Geographical, geological and hydrogeological setting}

Glòries Square is one of the main passages linking the city of Barcelona to the north and northeast, for both railway and road traffic (Fig. 1). A road tunnel is currently under construction to bypass the square and free the surface from traffic. The area is highly complex since it comprises several first-order infrastructures, many of which are quite ancient and thus weak as a result of age: 3 train tunnels, 1 metro tunnel, 1 main sewer and 1 main service gallery. The presence of these underground infrastructures has made it necessary for the new tunnel to pass underneath the square at an even greater depth. As a result, significant dewatering is needed, which might cause substantial ground settlements. In addition, over the last 15-20 years, some major public works accidents have occurred in Barcelona, rousing concern from both citizens and authorities. This situation has motivated the rigorous oversight of construction works.

Barcelona is located mainly on the Barcelona Plain, bounded by the Collserola range to the northwest (top of Fig. 1), the Mediterranean Sea to the southeast (bottom), the Besòs River to the northeast (right) and the Llobregat River to the southwest (left). The geology of the area can be divided into three levels from the surface down: anthropic fill, Quaternary units and Pliocene units. The anthropic fill is very heterogeneous in composition and thickness but no thicker than $6 \mathrm{~m}$. The Quaternary strata (Fig. 2) present an important lithological north-south-oriented change corresponding to the boundary of the Besòs River delta. On the eastern side of this boundary, the delta deposits consist mainly of three layers: well-sorted sands at the top and gravels at the bottom with silts and clays in between. On the western side, two units can be distinguished in the Barcelona Plain: dominant colluvial deposits originating from the erosion of the granites of the Collserola range and alluvial deposits associated with the drainage network. The colluvial deposits are very heterogeneous, varying from conglomerates to sandstones in a very abundant clayey matrix, and have a certain degree of cementation. The alluvial deposits constitute the fill of ancient streams and are composed mainly of gravels in a clayey matrix. Finally, the underlying Pliocene units (Fig. 2) constitute the pre-Quaternary substrate. These units are located at depths ranging from $10 \mathrm{~m}$ inland (Glòries Square) to $55 \mathrm{~m}$ near the sea. The topography of these strata changes from steep and rough near the Collserola range, where ancient streams eroded these units, to flat and smooth in the Besòs River delta 


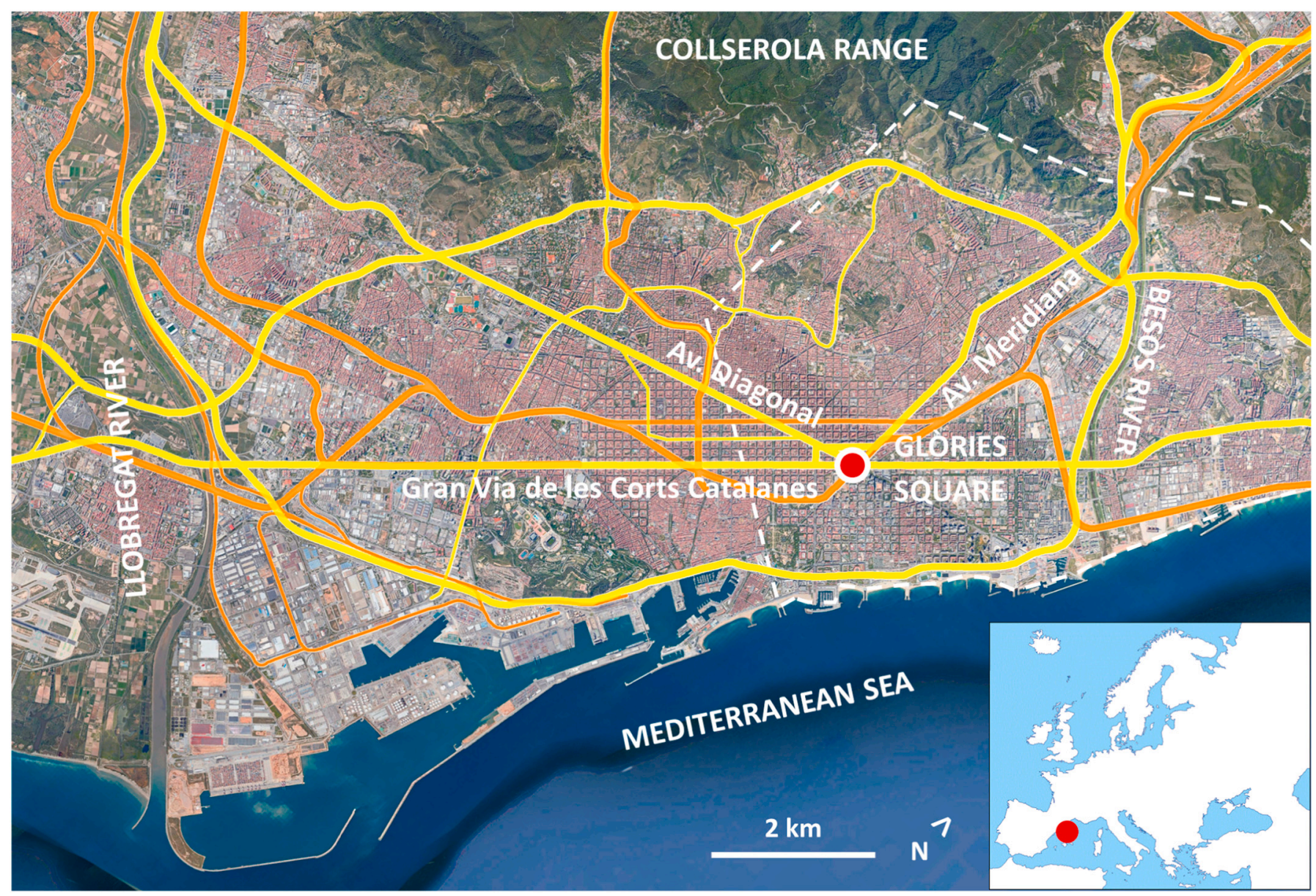

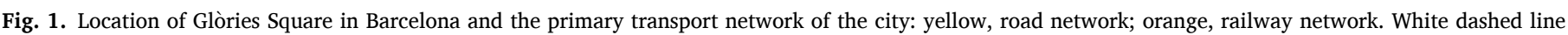
shows the location of Fig. 2. (Background image: Google Earth).

area, closer to the sea. Two Pliocene units can be identified: the upper unit consists of sands and gravels within a sandy clayey matrix, while the lower unit consists of clays and blue marls. Both Pliocene units are of marine origin. Two main fault families oriented northwest-southeast and southwest-northeast divide and compartmentalise these formations; between them, the northwest-southeast faults are more important. For a more detailed geological description, see Vàzquez-Suñé et al., 2016.

Glòries Square immediately overlies two important (hydro)geological features (Fig. 2): the boundary between the Besòs River delta and the Quaternary colluvial units; and a major northwest-southeasttrending fault truncating the underlying Pliocene strata, which also represents a change in the lithology from marls in the southwest to sandstones in the northeast. From a hydrogeological point of view, the Besòs River delta can be described as overlying three aquifers separated by two aquitards whose thicknesses increase towards the sea (Velasco et al., 2012). Given that Glories Square is situated at the edge of the delta, the aquitards virtually disappear beneath the square, and thus, all three aquifers connect (Fig. 3) in a zone where all Quaternary deposits have a limited thickness. There are five recharge sources in this area: infiltration of rainfall in the Collserola range, leaks from the water supply and sewer networks, recharge from the Besòs River (which is, to a great extent, composed of treated wastewater), urban runoff, and marine intrusion (Vàzquez-Suñé et al., 2010). Under undisturbed conditions, the main groundwater flux travels from the Collserola range to the Mediterranean Sea (northwest to southeast), except for the areas surrounding the Besòs River, where the interaction with the river dominates the local piezometry.

\subsection{Civil works description}

The works in Glòries Square consist of the construction of a tunnel by the cut-and-cover method, except for three sections passing under crossing pre-existing tunnels (orange area and circles in Fig. 4). During the study period (until autumn 2018), the works were limited mainly to Glòries Square itself (green area in Fig. 4), although the total extent of the construction site will be greater (with the addition of the red area in Fig. 4). Thus, the excavation during the study period was $500 \mathrm{~m}$ long, 25 $\mathrm{m}$ wide and up to $30 \mathrm{~m}$ deep (under the pre-existing tunnels), with the deepest retaining walls reaching depths up to $50 \mathrm{~m}$. This implies that, although only Quaternary deposits were drained in most of the area affected by the dewatering of the excavation, the underlying Pliocene materials were also drained in the excavation area itself.

The retaining walls have some shallower sections, with the walls resembling a comb in profile view, aiming to minimise the obstruction of the aquifers (note that the axis of the tunnel is perpendicular to the main groundwater flux). These walls are convenient from not only a construction point of view -making the excavation easier, cheaper and safer- but also from a hydrological point of view. To a certain degree, an enclosure isolates the excavation from the surroundings in such a way that the volume to be drained is reduced -minimising the economic cost- and the drawdown outside the enclosure decreases -thereby reducing the deformation of the terrain. In Glòries Square, the retaining walls are slurry walls.

Prior to the construction works, in August 2015, the water table was at a depth of $14 \mathrm{~m}$ beneath Glòries Square, which implies the need for 16 $\mathrm{m}$ of lowering at the lowest point. The dewatering of the excavation 


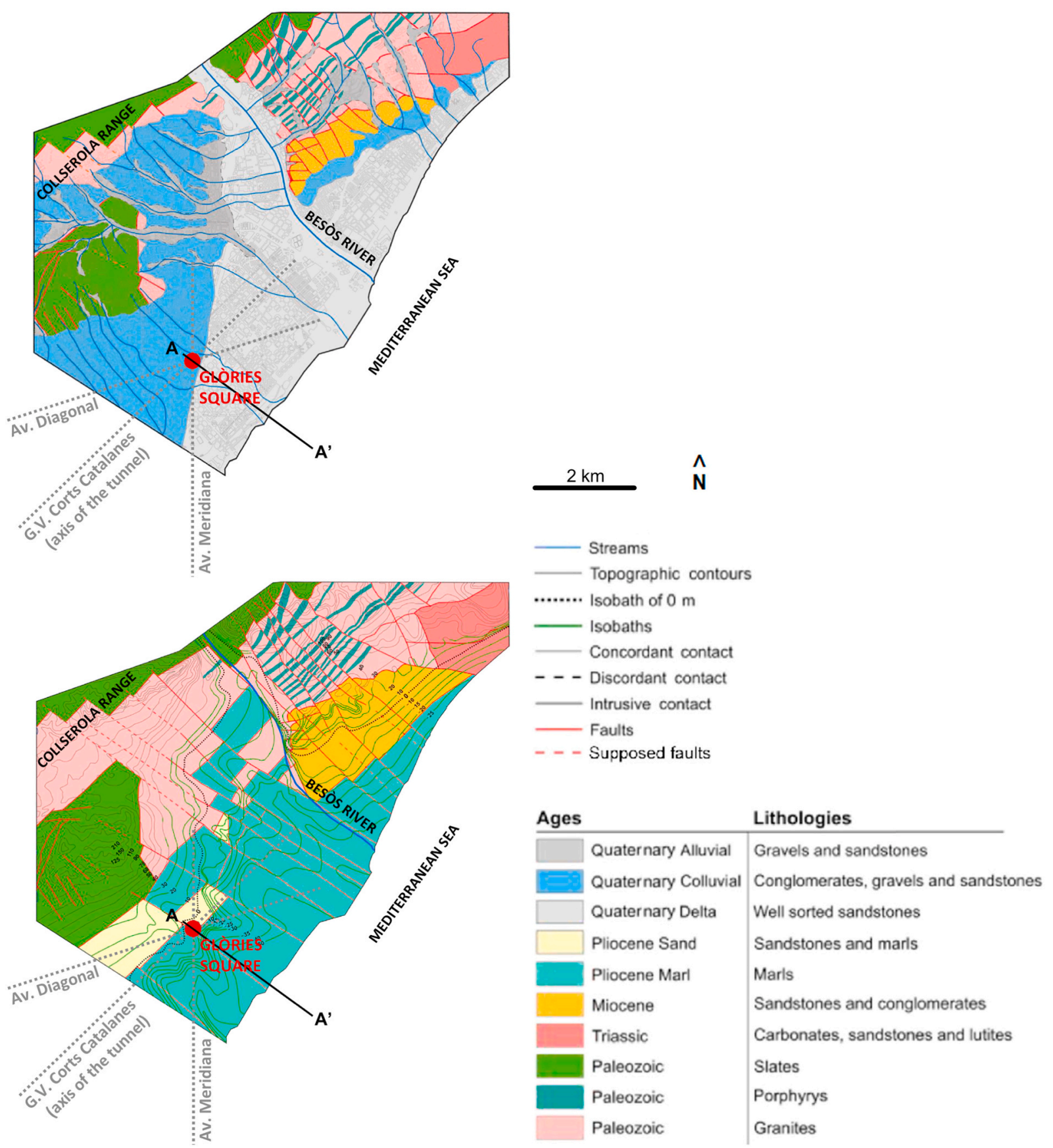

Fig. 2. Geological context, with (top) and without (bottom) the Quaternary deposits. See location in Fig. 1. Hydrogeological cross-section A-A' is shown in Fig. 3. (Modified from Vàzquez-Suñé et al., 2016).

began on 23/01/2017. Until the works were temporarily stopped in May $2017,1 \mathrm{hm}^{3}$ of water was drained by up to 36 wells during the transient stage (yellow and red points in Fig. 4). Some of these wells are located within the enclosure, while some are situated outside (at the junctions with the crossing pre-existing tunnels). All of the wells are screened all along their lengths (except for the deepest metre). During this first dewatering stage, the total discharge rate ranged from 30 to $420 \mathrm{~L} / \mathrm{s}$ (Fig. 9). The works resumed in March 2018 and were expected to proceed for 32 months. This paper is focused on this second dewatering stage, in which the stabilised pumping rate was approximately $155 \mathrm{~L} / \mathrm{s}$ distributed among 13 wells (red points in Fig. 4). Note that the density of pumping wells is greater in the northeastern part of the excavation (right-hand side in Fig. 4), reflecting the change in transmissivity between the colluvial and deltaic materials, with the transmissivity being much greater in the latter.

\subsection{Data}

To monitor potential ground movements during the construction of the tunnel, the Glòries Square area has been monitored with D-InSAR since May 2015 (Fig. 5). The processed dataset is composed of 97 descending interferometric wide swath (IWS) single look complex (SLC) Sentinel-1A images from 06/03/2015 to 28/09/2018 (Table 1). Five other images were discarded due to strong atmospheric effects (noimage-number entries in Table 1). For most of the images, the time separation was 12 days, even though in some cases it was either 6 or 24 days.

The applied SAR data processing scheme is the persistent scatterer 

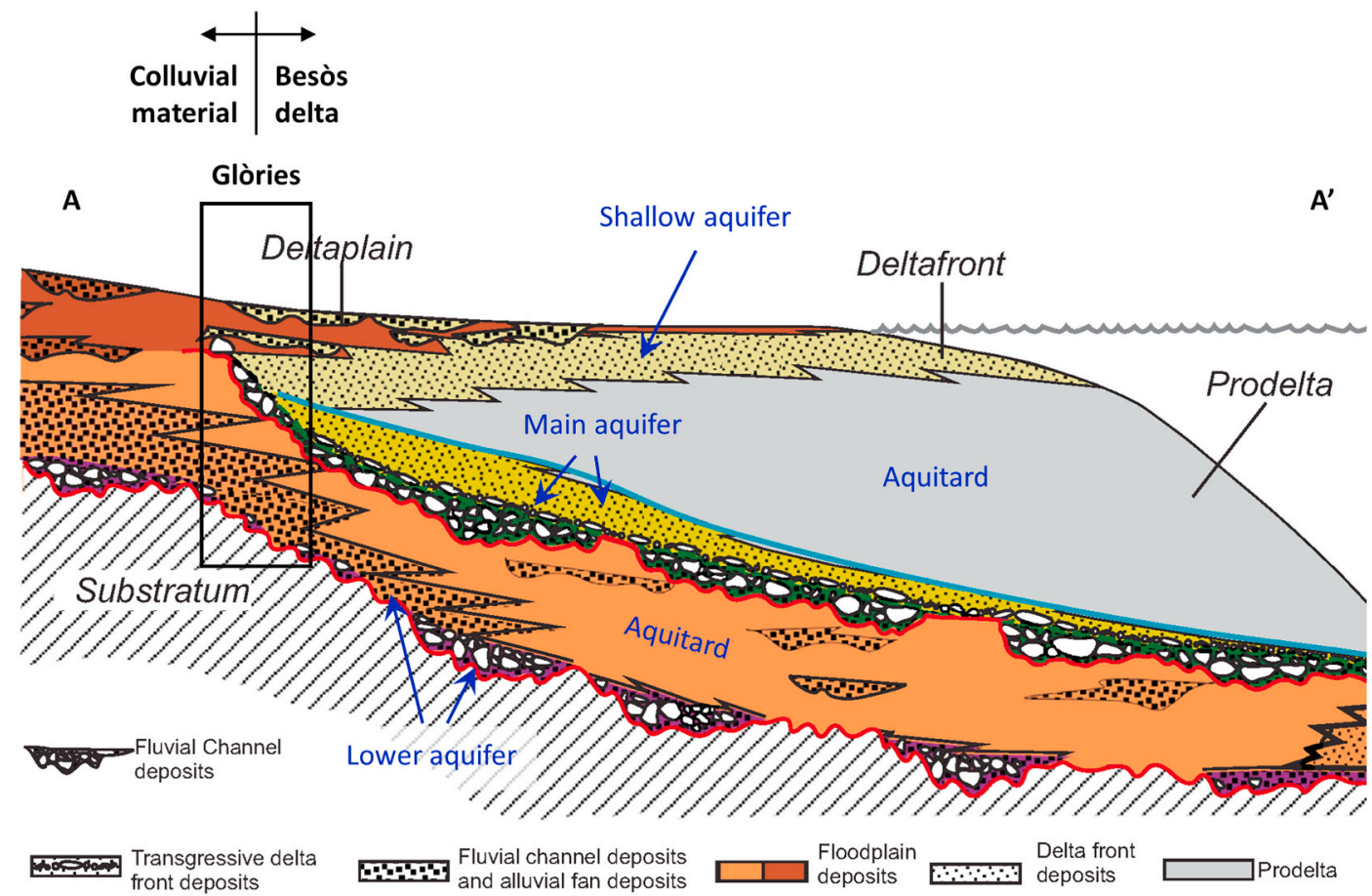

Fig. 3. Schematic hydrogeological cross-section of the Quaternary deposits. In reality, in the area of Glòries Square, the Quaternary strata have a reduced thickness, and the lower aquitard no longer isolates the lower aquifer from the main aquifer. Approximate scale: $4 \mathrm{~km} \times 100 \mathrm{~m}$. See location in Fig. 2. (Modified from Velasco et al., 2012).

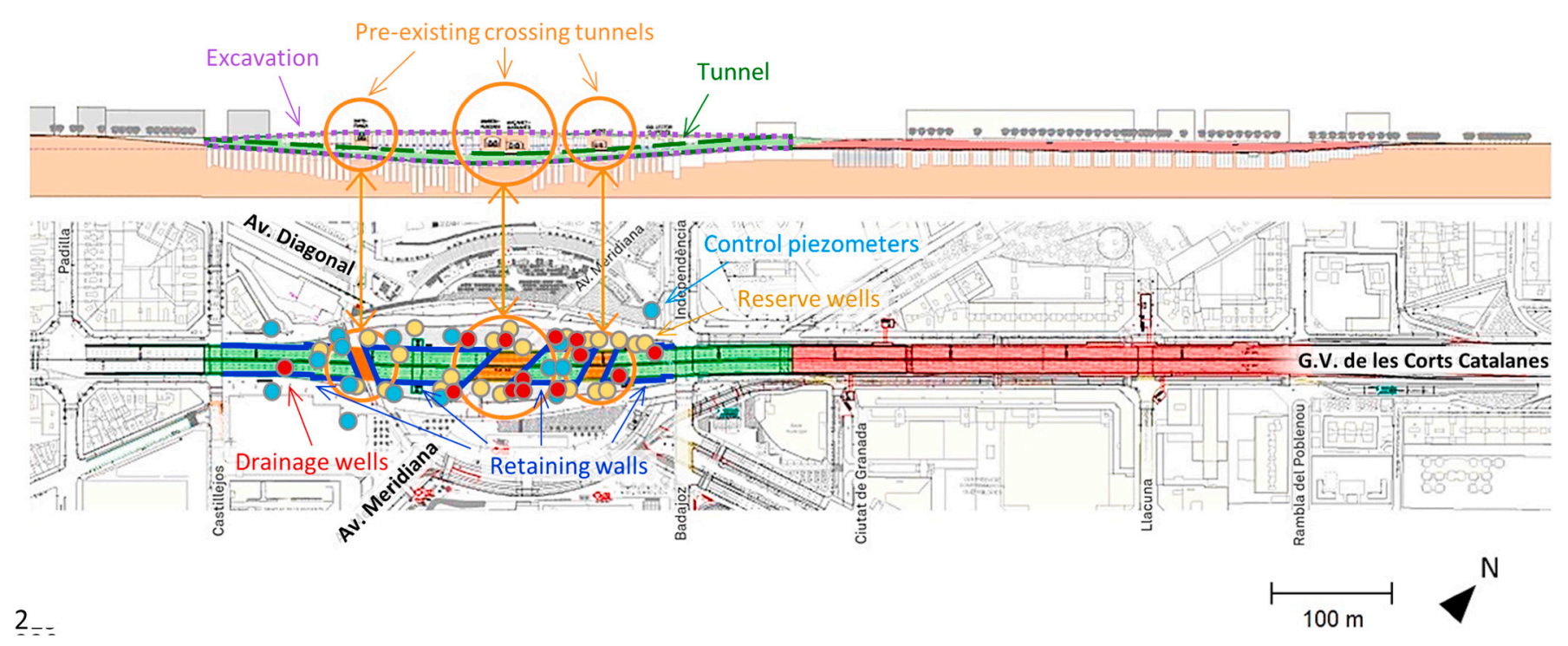

Fig. 4. Geometry of the construction works and drainage network. Top: cross-section; bottom: plan view. Green: area under construction during the study period; red: area not yet under construction during the study period. See location in Fig. 5. (Modified from BIMSA, Ajuntament de Barcelona).

interferometry (PSI) technique described in detail in Crosetto et al., 2018 and Devanthéry et al., 2014. The main steps are as follows:

(1) Precise co-registration of the images based on the information provided by the orbits.

(2) Generation of two redundant networks of interferograms: fullresolution or single-look (pixel footprint: 4 by $14 \mathrm{~m}$ ) interferograms and 10 in range by 2 in azimuth $(10 \times 2)$ multi-look (pixel footprint: 40 by $28 \mathrm{~m}$ ) interferograms.

(3) Candidate persistent scatterer (PS) selection based on SAR amplitude dispersion.
(4) $2 \mathrm{D}+1 \mathrm{D}$ (space + time) phase unwrapping of redundant $10 \times 2$ multi-look interferograms.

(5) Identification of stable areas in the areas surrounding the region of interest. In this case, according to the piezometric maps (Fig. 7), it was assumed that no deformation takes place farther than $1 \mathrm{~km}$ from Glòries Square.

(6) Estimation of the atmospheric phase component over stable areas (in this case, assuming a spatial linear phase model).

(7) Prediction and removal of the estimated atmospheric component from the original single-look interferograms. 


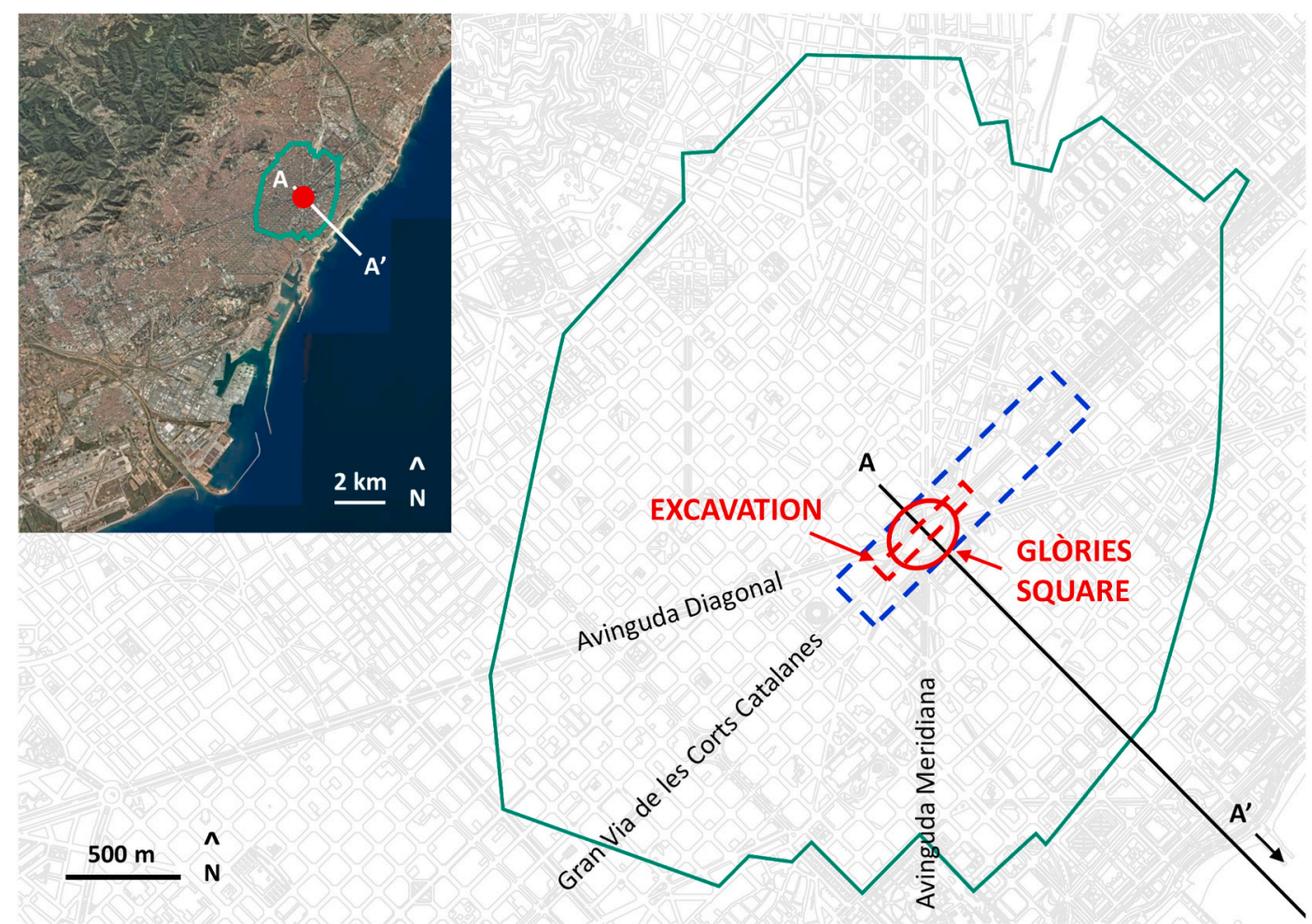

Fig. 5. Area studied with D-InSAR (green line) within Barcelona. Red ellipse: Glòries Square. Red rectangle: excavation. Blue rectangle: extents of Fig. 4 and Fig. 10. (Embedded satellite image: ESRI; background main image: Ajuntament de Barcelona).

Table 1

List of the IWS SLC Sentinel-1A SAR images used in this study. The no-image-number entries were discarded because of strong atmospheric effects.

\begin{tabular}{|c|c|c|c|c|c|c|c|c|c|c|c|}
\hline Image & Orbit & Date & Image & Orbit & Date & Image & Orbit & Date & Image & Orbit & Date \\
\hline 1 & 6,132 & $29 / 05 / 2015$ & 26 & 11,207 & $11 / 05 / 2016$ & 51 & 15,932 & $31 / 03 / 2017$ & 76 & 20,482 & $06 / 02 / 2018$ \\
\hline 2 & 6,307 & $10 / 06 / 2015$ & 27 & 11,382 & $23 / 05 / 2016$ & 52 & 16,107 & $12 / 04 / 2017$ & 77 & 20,657 & $18 / 02 / 2018$ \\
\hline 3 & 6,657 & 04/07/2015 & 28 & 11,557 & $04 / 06 / 2016$ & 53 & 16,282 & $24 / 04 / 2017$ & 78 & 20,832 & $02 / 03 / 2018$ \\
\hline 4 & 6,832 & $16 / 07 / 2015$ & 29 & 11,907 & $28 / 06 / 2016$ & 54 & 16,457 & $06 / 05 / 2017$ & 79 & 21,007 & $14 / 03 / 2018$ \\
\hline \multirow[t]{2}{*}{5} & 7,007 & $28 / 07 / 2015$ & 30 & 12,082 & $10 / 07 / 2016$ & 55 & 16,632 & $18 / 05 / 2017$ & 80 & 21,182 & $26 / 03 / 2018$ \\
\hline & 7,182 & 09/08/2015 & 31 & 12,257 & $22 / 07 / 2016$ & & 16,807 & $30 / 05 / 2017$ & 81 & 21,357 & $07 / 04 / 2018$ \\
\hline 6 & 7,357 & $21 / 08 / 2015$ & 32 & 12,432 & $03 / 08 / 2016$ & 56 & 16,982 & $11 / 06 / 2017$ & 82 & 21,532 & $19 / 04 / 2018$ \\
\hline 7 & 7,707 & $14 / 09 / 2015$ & 33 & 12,607 & $15 / 08 / 2016$ & 57 & 17,157 & $23 / 06 / 2017$ & 83 & 21,707 & $01 / 05 / 2018$ \\
\hline 8 & 7,882 & $26 / 09 / 2015$ & 34 & 12,782 & $27 / 08 / 2016$ & 58 & 17,332 & $05 / 07 / 2017$ & 84 & 21,882 & $13 / 05 / 2018$ \\
\hline 9 & 8,057 & $08 / 10 / 2015$ & 35 & 12,957 & 08/09/2016 & 59 & 17,507 & $17 / 07 / 2017$ & 85 & 22,057 & $25 / 05 / 2018$ \\
\hline 10 & 8,407 & $01 / 11 / 2015$ & 36 & 13,132 & $20 / 09 / 2016$ & 60 & 17,682 & $29 / 07 / 2017$ & & 22,232 & $06 / 06 / 2018$ \\
\hline 11 & 8,582 & $13 / 11 / 2015$ & & 13,307 & $02 / 10 / 2016$ & 61 & 17,857 & $10 / 08 / 2017$ & 86 & 22,407 & $18 / 06 / 2018$ \\
\hline 12 & 8,757 & $25 / 11 / 2015$ & 37 & 13,482 & $14 / 10 / 2016$ & 62 & 18,032 & $22 / 08 / 2017$ & 87 & 22,582 & $30 / 06 / 2018$ \\
\hline 13 & 8,932 & $07 / 12 / 2015$ & 38 & 13,657 & $26 / 10 / 2016$ & 63 & 18,207 & 03/09/2017 & 88 & 22,757 & $12 / 07 / 2018$ \\
\hline 14 & 9,107 & $19 / 12 / 2015$ & 39 & 13,832 & $07 / 11 / 2016$ & 64 & 18,382 & $15 / 09 / 2017$ & 89 & 22,932 & $24 / 07 / 2018$ \\
\hline 15 & 9,282 & $31 / 12 / 2015$ & 40 & 14,007 & $19 / 11 / 2016$ & 65 & 18,557 & $27 / 09 / 2017$ & 90 & 23,107 & $05 / 08 / 2018$ \\
\hline 16 & 9,457 & $12 / 01 / 2016$ & 41 & 14,182 & $01 / 12 / 2016$ & 66 & 18,732 & 09/10/2017 & 91 & 12,211 & $11 / 08 / 2018$ \\
\hline 17 & 9,632 & $24 / 01 / 2016$ & 42 & 14,357 & $13 / 12 / 2016$ & 67 & 18,907 & $21 / 10 / 2017$ & 92 & 23,282 & $17 / 08 / 2018$ \\
\hline 18 & 9,807 & $05 / 02 / 2016$ & 43 & 14,532 & $25 / 12 / 2016$ & 68 & 19,082 & $02 / 11 / 2017$ & 93 & 12,386 & $23 / 08 / 2018$ \\
\hline 19 & 9,982 & $17 / 02 / 2016$ & 44 & 14,707 & $06 / 01 / 2017$ & 69 & 19,257 & $14 / 11 / 2017$ & & 12,561 & $04 / 09 / 2018$ \\
\hline 20 & 10,157 & $29 / 02 / 2016$ & 45 & 14,882 & $18 / 01 / 2017$ & 70 & 19,432 & $26 / 11 / 2017$ & 94 & 23,632 & $10 / 09 / 2018$ \\
\hline 21 & 10,332 & $12 / 03 / 2016$ & 46 & 15,057 & $30 / 01 / 2017$ & 71 & 19,607 & $08 / 12 / 2017$ & 95 & 12,736 & $16 / 09 / 2018$ \\
\hline 22 & 10,507 & $24 / 03 / 2016$ & 47 & 15,232 & $11 / 02 / 2017$ & 72 & 19,782 & $20 / 12 / 2017$ & 96 & 23,807 & $22 / 09 / 2018$ \\
\hline 23 & 10,682 & $05 / 04 / 2016$ & 48 & 15,407 & $23 / 02 / 2017$ & 73 & 19,957 & $01 / 01 / 2018$ & 97 & 12,911 & $28 / 09 / 2018$ \\
\hline 24 & 10,857 & $17 / 04 / 2016$ & 49 & 15,582 & $07 / 03 / 2017$ & 74 & 20,132 & $13 / 01 / 2018$ & & & \\
\hline 25 & 11,032 & $29 / 04 / 2016$ & 50 & 15,757 & $19 / 03 / 2017$ & 75 & 20,307 & $25 / 01 / 2018$ & & & \\
\hline
\end{tabular}

(8) Estimation of the linear deformation velocity and residual topographic error (RTE) using atmosphere-free single-look interferograms.

(9) Removal of the RTE from the atmosphere-free single-look interferograms.

(10) $2 \mathrm{D}+1 \mathrm{D}$ phase unwrapping of the RTE- and atmosphere-free single-look interferograms.
(11) Generation of the deformation time series and estimation of the deformation velocity.

(12) Geocoding of the results.

A final smoothing procedure was applied to the resulting time series to remove noise that hindered the interpretation of the results, especially regarding the spatial distribution. The term noise here refers to 
any contribution not strictly related to the deformation process, including residual atmospheric effects, residual orbital errors, residual topographic errors, phase unwrapping errors, phase noise, etc. Some of these sources show a correlation in time and/or space, while others do not. Therefore, since smoothing is applied to the time series individually and independently (i.e., without involving any spatial consideration), the smoothing procedure reduces only the noise that is temporally uncorrelated (i.e., temporally independent). However, most of this temporally uncorrelated noise appears to be spatially correlated in the case of Glòries Square, and thus, smoothing clearly improved the maps.

The smoothing procedure consisted of two steps: first, a moving median over 5 dates of data acquisition; second, a moving average over 3 dates. The width of the moving median ( 5 dates) and the fitting of the smoothing were calibrated and verified using 14 control time series grouped into 7 pairs distributed across the entire study area. Each pair contained two close points, one point with large noise and another one with small noise. The selected control time series and the groups of pairs were chosen to obtain a control data subset representative of the whole dataset based on the map of noise. The first step removes most of the noise, but the time series become rough; then, in the second step, the moving average is applied over 3 dates to smooth the time series while altering them the least.

In the analysis of the results, other data were used: geological data, hydraulic parameters of the terrain, piezometric data and levelling measurements. Velasco et al., 2012 and Vàzquez-Suñé et al., 2016 performed a local revision of the geology and built a numerical hydrogeological model of the Besòs River delta and its surroundings. From this information, from data obtained through new boreholes drilled for the works in Glòries Square, and from pumping tests on some of the drainage wells, a refined local hydrogeological model was established (IDAEA-CSIC, 2015; IDAEA-CSIC, 2016). The hydraulic parameters of the terrain, such as the transmissivity and storage coefficient, were extracted from this refined model, the values of which are consistent with the hydraulic parameterisation of other tunnelling works in the vicinity (Pujades et al., 2014b, 2015, 2016).

The CM office provided the geometry of the works and structures included in the numerical model. These data were taken into account in the interpretation of the field measurements. The CM office also provided the locations of the drainage wells and monitoring piezometers in addition to time series of the pumping discharge rates and groundwater heads. These data were complemented with periodic field campaigns in the areas surrounding the works, both before and during the construction, thereby providing a wider spatial and temporal context. These campaigns monitored, among other parameters, the groundwater head, i.e., the piezometry and its evolution.

Finally, the CM office also provided the locations of the points within the levelling monitoring network and their deformation time series, which have allowed a comparison with the D-InSAR results. This dataset consists of a network of 170 monitored levelling bolts fixed to building façades along the axis of the tunnel (Fig. 10) and a network of 36 reference bases fixed to the ground located within an approximate distance of $450 \mathrm{~m}$ throughout Glòries Square.

\section{Results and discussion}

\subsection{Hydrogeological analysis}

One of the D-InSAR products is a map of accumulated displacement of the ground surface in the form of a cloud of georeferenced points or pixels. In the case discussed here, the D-InSAR results show up to $-7 \mathrm{~mm}$ settlement immediately eastward of Glòries Square (Fig. 6). The remainder of the observed scene is approximately stable.

In the presented case study, the deformation is expected a priori to be related to the drawdown caused by the dewatering of the civil works. Thus, upon analysing the spatial distribution of deformation, one of the most surprising D-InSAR results might be that the settlement is not centred and distributed around the construction area but is instead concentrated in the east quadrant (Fig. 6). Nevertheless, this outcome is

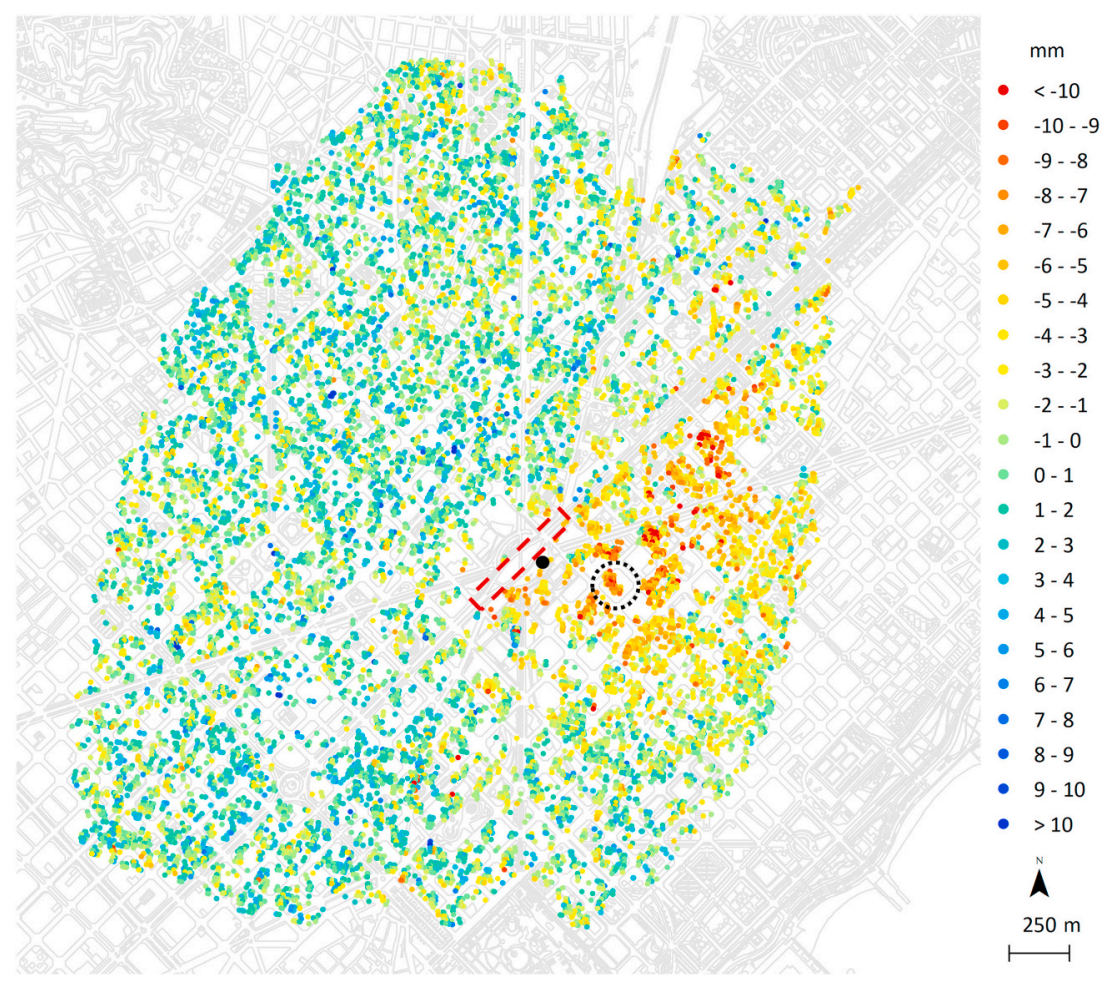

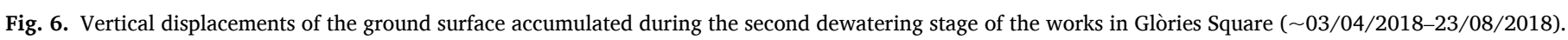

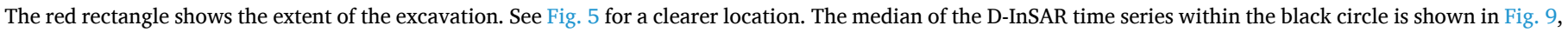
as well as the water head time series of the black point. (Background image: Ajuntament de Barcelona). 
in good agreement with the local geology and the observed drawdown.

Regarding the geology, three aspects are relevant. First, the Quaternary deposits east of Glòries Square correspond to the Besòs River delta (Fig. 2), which is formed by three aquifers separated by two aquitards (Fig. 3). At the district scale (Fig. 5 to Fig. 8), drawdown occurs mainly in these Quaternary deposits, although Pliocene materials are also drained at the construction site scale. In particular, within the delta, dewatering of the construction works in Glòries Square drains the shallow deltaic aquifer, which also affects the upper aquitard. As a finegrained unit, the aquitard is more deformable than the surrounding colluvial materials of the Barcelona Plain, i.e., west of Glòries Square. Second, these colluvial materials comprise several cemented levels that increase their stiffness. Together, these two aspects lead to larger settlement east of Glòries Square, even if drawdown was uniform. Third, the shallow deltaic aquifer is more transmissive than the colluvial and alluvial materials of the Barcelona Plain, which result in a greater extent of drawdown, i.e., a more extensive cone, east of the excavation.

Regarding the piezometry, the spatial distribution of deformation strongly agrees with that of the drawdown measured in the field (Fig. 7). The phreatic surface was determined by manually measuring the water head at two sets of piezometers: the control network of the construction works and the control network of the City Council of Barcelona (Ajuntament de Barcelona). In the latter case, the piezometers are shallow and measure the water head of the shallow aquifer, whereas in the former case, the piezometers are deeper (up to $40 \mathrm{~m}$ deep) and measure the head of the merged lower, main and shallow aquifers. The drawdown distribution is attributed to three possible reasons. First, the natural groundwater flux travels from northwest to southeast (i.e., towards the Mediterranean Sea). Second, the lithology is more transmissive eastward. Third, several other dewatering operations southeast and east of Glòries Square followed one another since the 2000s, even though the dewatering operation in Glòries Square is much larger in both extent and magnitude. These successive third-party dewaterings may explain why the largest deformation is detected not within the construction area itself (the centre of the current piezometric cone) but towards the southeast, especially upon taking into account that the largest settlement occurs where a piezometric depression cone was already detected before the construction works in Glòries Square began (Fig. 8).

D-InSAR can also provide the time series of the accumulated displacement at each point or pixel. These results show that the evolution of the deformation in the area of Glories Square follows that of the water table, which in turn is opposed to that of the drainage discharge rate (Fig. 9). This correlation confirms that the drawdown related to the works in Glòries Square dominates the dynamics of the area, despite the existence of several other dewatering operations nearby. In summary, the local geology and piezometry perfectly explain the observations made by D-InSAR in both space and time.

The temporal evolution also justifies why this paper can easily focus only on the second dewatering stage of the construction works in Glòries Square, i.e., since the works resumed in March 2018 after a temporary cessation spanning some months: the ground surface fully recovered from the settlement produced during the first stage before the second stage began (Fig. 9) in such a way that the deformation described in this paper is related only to the second stage (at least, regarding the works in Glòries Square). This also means that the deformation that occurred during the first stage of dewatering was reversible, which will be recalled later in the discussion. The largest settlement since the second stage began $(\sim 03 / 04 / 2018)$ reached $-7 \mathrm{~mm}$ by the end of August 2018 , very similar to the value of $-7.5 \mathrm{~mm}$ observed during the first dewatering stage.

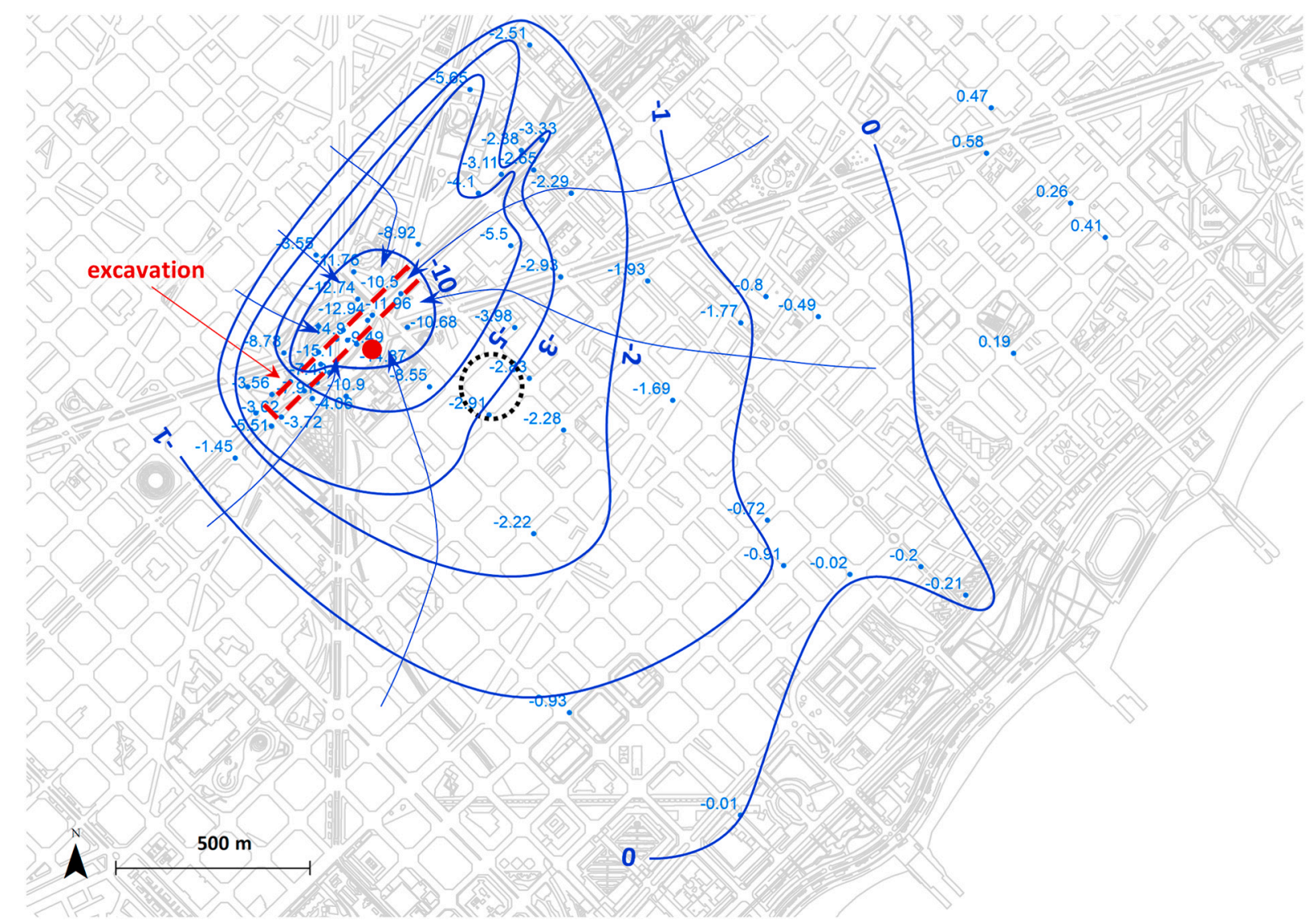

Fig. 7. Phreatic surface of the study area in November 2018. Levels are expressed in metres above sea level (m.a.s.l.). The time series of the red dot (black dot in Fig. 6) is shown in Fig. 9. The black circle is the same as that in Fig. 6 and Fig. 8. (Background image: Ajuntament de Barcelona). 


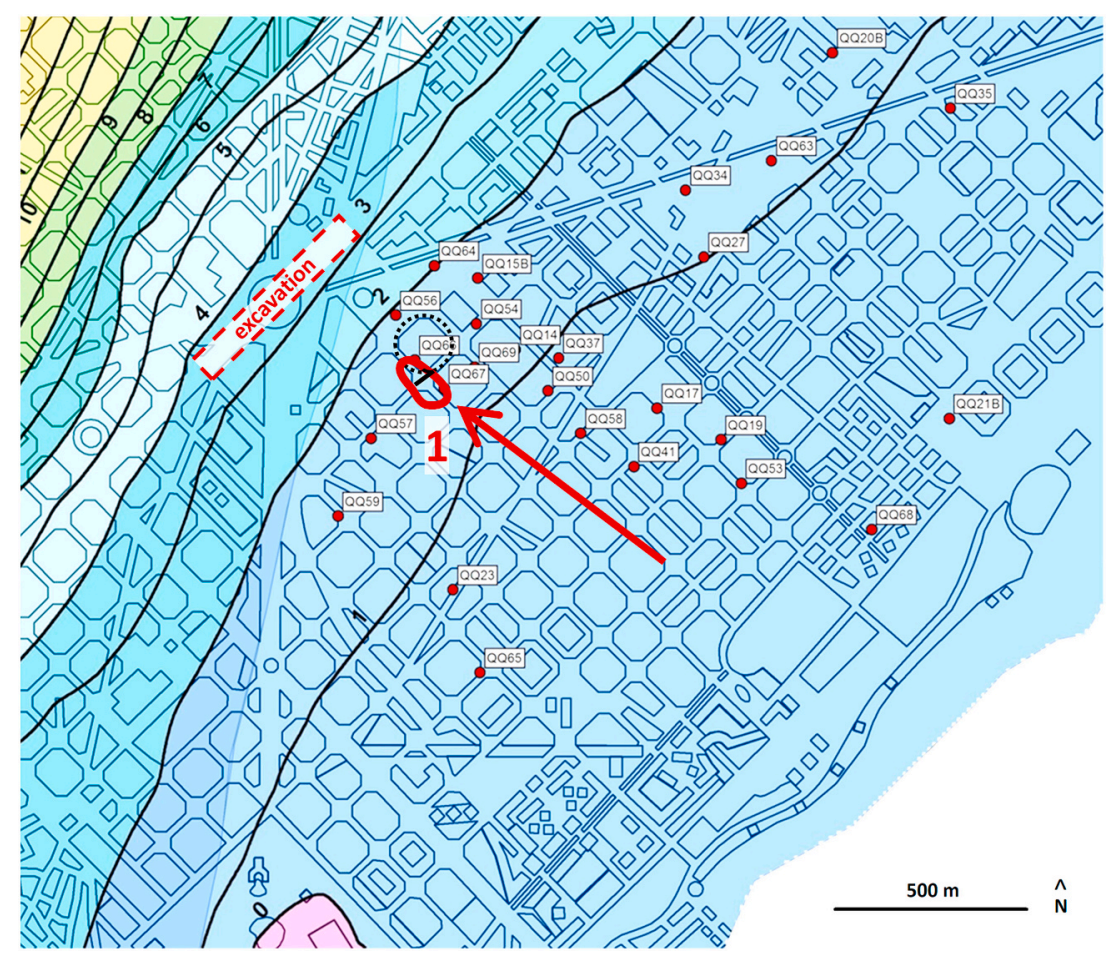

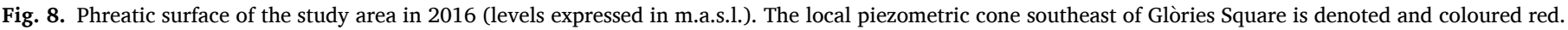

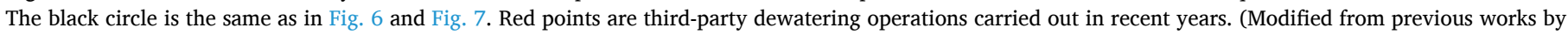
IDAEA-CSIC).

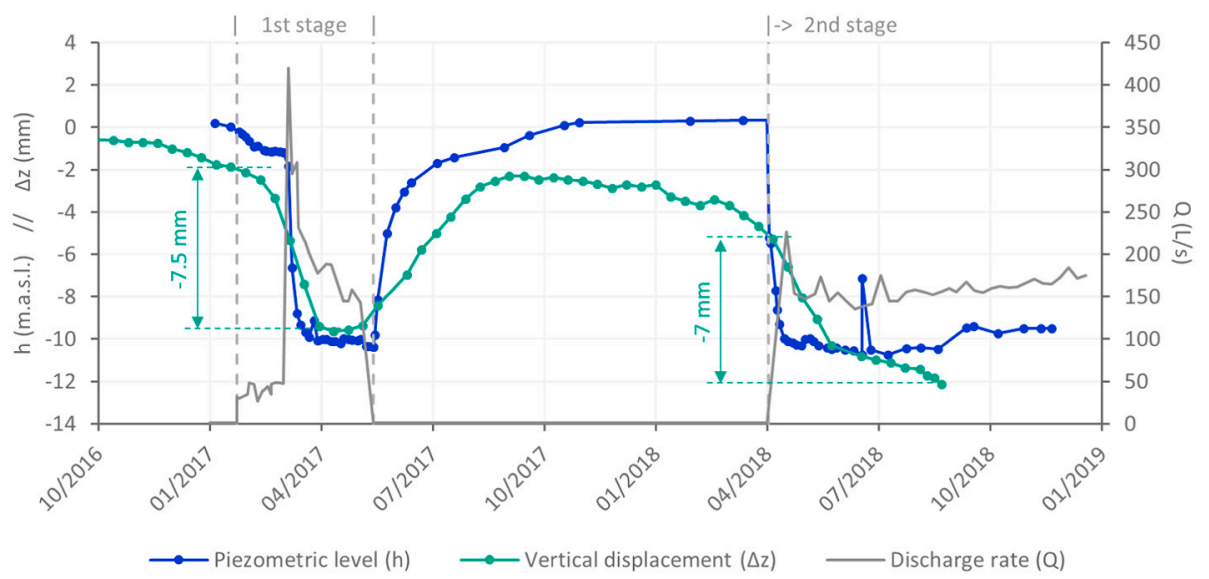

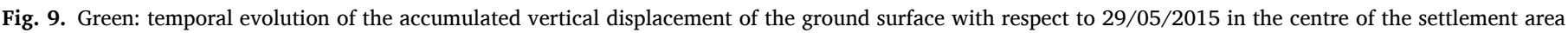

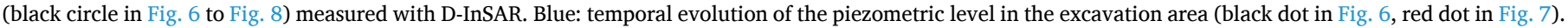
Grey: temporal evolution of the total dewatering pumping rate during the works of Glòries Square.

\subsection{Comparison with levelling data}

Available levelling data from the monitoring of the works allow a comparison with the D-InSAR results. Since these levelling data are concentrated along the axis of the tunnel (Fig. 10), the comparison is based on two profiles along the tunnel, one on the northwest ("mountain") side and one on the southeast ("sea") side (Fig. 11). Consequently, whereas the preceding analysis has been focused on the district scale, the subsequent analysis is focused on the excavation scale.

When analysing the results, especially when comparing the D-InSAR and levelling results, it must be kept in mind that both techniques measure specific points that might not strictly follow the areal trend depending on their physical support and its mechanical bond with the surroundings. For instance, one point can be located on the sidewalk of a street, while another point can be located on the roof of an adjacent building; given that the former is located directly on the terrain, whereas the latter is on a structure with a foundation, the ground deformation at these two points can be different. The same situation arises if two close points are located on two different buildings with foundations on different strata. This is especially relevant in the case of D-InSAR because there is no prior control on the locations of the measuring points (pixels or PSs, in this case) and because each pixel of a SAR image usually contains several scatterers or reflectors -more or less depending on the observed scene and the spatial resolution of the image. For this reason, the profiles are built with the measurements located in an approximately $25 \mathrm{~m}$ wide band along the tunnel and then synthesised (Fig. 11). The results of each technique differ in two aspects: the spatial pattern and the magnitude of ground movement. 


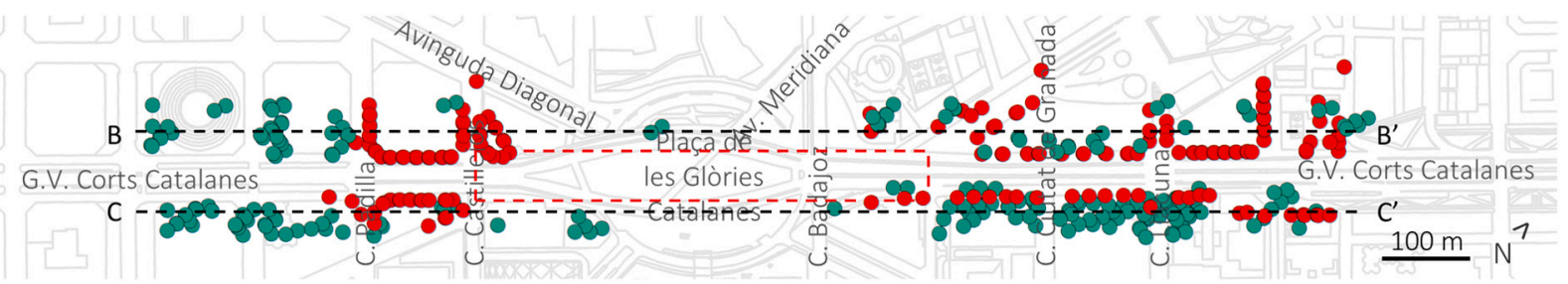

Fig. 10. Points included in the profiles presented in Fig. 11: green, D-InSAR; red, levelling. The red rectangle shows the extent of the excavation. See the location of this map in Fig. 5.
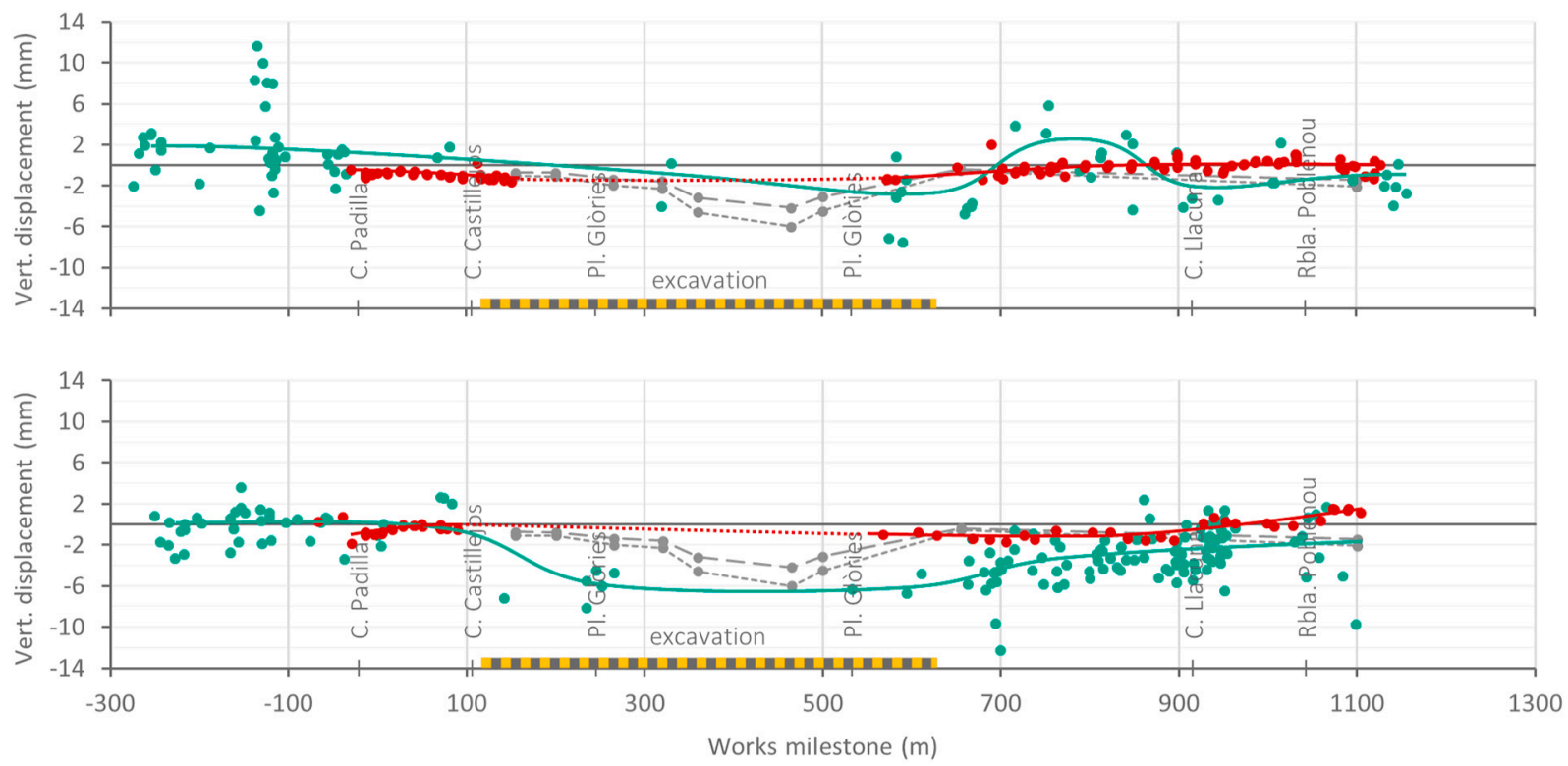

- InSAR

Leveling

InSAR interpolation

Levelling interpolation ------- Analytical $-\rightarrow-$ - Analytical*

Fig. 11. Profiles of the vertical displacement of the ground surface along the tunnel accumulated during dewatering (2nd stage, between $07 / 04 / 2018$ and $05 / 08 /$ 2018). Top, B-B', northwest side; bottom, C-C', southeast side (see Fig. 10). Green, D-InSAR; red, levelling. Coloured lines are interpolations based on the median. The profiles in grey (included for comparison) are analytical estimations (Fig. 12) along a profile centred in the tunnel (i.e., between B-B' and C-C').

Regarding the spatial pattern, the D-InSAR profiles show greater settlement on the southeast side with a maximum of $-7 \mathrm{~mm}$ versus a maximum of $-3 \mathrm{~mm}$ on the northwest side (Fig. 11). However, this pattern is not observed in the levelling profiles, in which the largest settlement reaches -1 to $-2 \mathrm{~mm}$ on both sides. Again, the pattern described by D-InSAR (reflecting greater deformation on the southeast side) correlates with the local hydrogeology, now -at construction site scale- regarding not only the Quaternary deposits but also the Pliocene strata. As stated previously, at the construction site, drawdown occurs not only in the Quaternary deposits but also in the Pliocene strata, which is relevant since the axis of the tunnel northeast of Glòries Square is aligned with a fault delineating a lithological change in the Pliocene strata (Fig. 2) from sands on the northwest side to marls on the southeast side, i.e., more deformable materials on the southeast side. Nevertheless, it is worth noting that the largest settlement within the profiles occurs in Glòries Square, as shown by the D-InSAR results, exactly where no levelling measuring points are available (Fig. 11). In other words, DInSAR data allow the ground deformation in the construction area to be described, whereas -in this case- levelling does not. Note also that these profiles do not cross the centre of the settlement zone (Fig. 6), so they do not reflect the absolute peak deformation within the monitored area.

Regarding the magnitude of ground movement, the amount of settlement is rather small, and therefore, it is difficult to judge the discrepancy between the D-InSAR and levelling data. Nevertheless, the settlement was estimated analytically to obtain a third value to compare their results. The settlement at the top of a ground layer $(\Delta z[\mathrm{~L}])$ related to a given drawdown can be estimated with the equation proposed by Cashman and Preene, 2001:

$\Delta z=\gamma_{w} \cdot b \cdot \alpha \cdot \Delta h$

where $\gamma_{w}$ is the specific weight of water $\left[\mathrm{L}^{-2} \mathrm{MT}^{-2}\right], b$ is the thickness of the layer [L], $\alpha$ is the compressibility coefficient of the ground $\left[\mathrm{LM}^{-1}\right.$ $\mathrm{T}^{2}$ ], and $\Delta h$ is the drawdown [L]. The compressibility coefficient can be associated with the storage coefficient $(S[])$ according to the formula proposed by Jacob, 1950 and cited by Ferris et al., 1962:

$S=\rho_{w} \cdot g \cdot b \cdot\left(\alpha+\theta \cdot \beta_{w}\right)$

where $\rho_{w}$ is the density of water $\left[\mathrm{L}^{-3} \mathrm{M}\right], g$ is the gravitational acceleration $\left[\mathrm{LT}^{-2}\right], \theta$ is the porosity of the medium [], and $\beta_{w}$ is the compressibility coefficient of water $\left[\mathrm{LM}^{-1} \mathrm{~T}^{2}\right]$. Considering that the compressibility of water is usually much smaller than that of the ground, the former is commonly neglected, leading to the following simplification:

$S \approx \rho_{w} \cdot g \cdot b \cdot \alpha=\gamma_{w} \cdot b \cdot \alpha$

Finally, the settlement at the ground surface is estimated as the sum of the settlement occurring in each layer:

$\Delta z=\sum_{i}\left(S_{i} \cdot \Delta h_{i}\right)$ 
where the index $i$ refers to the i-th hydrogeological layer.

The proposed procedure needs some clarifications. First, regarding Eq. (4), in a general case, the storage coefficient $(S)$ is not constant; therefore, the equation is not linear. As the aquifer is compacted due to drawdown and the subsequent increase in the effective stress, the aquifer becomes stiffer, and the storage coefficient diminishes, describing a logarithmic relationship between the stress (drawdown) and deformation (settlement) (Dassargues, 1995). However, in the case of Glòries Square, a constant value for the storage coefficient is used. This value was obtained through an inverse calibration using the local numerical hydrogeological model specifically developed for designing the dewatering of the construction works in Glòries Square. The data used for the calibration were obtained from pumping tests performed in the wells of the works. These tests registered both the drawdown until stabilisation of the groundwater level and the recovery and were performed with a discharge rate similar to that expected for dewatering. Thus, the storage coefficient obtained from the interpretation of these tests is unaltered, valid for the applied stresses, and representative of the whole area affected by the pumping. Therefore, the obtained value for the storage coefficient can be assumed to be an average value valid to be used as a constant in Eq. (4).

The second clarification is with regard to the Eq. (1). This formula assumes that the deformation is purely vertical. This simplification is rather common yet not always true. In the general case of an aquifer where the boundaries do not constrain the deformation of the soil, deformation will occur in both the vertical and the horizontal directions (Pujades et al., 2017). Since the storage coefficient obtained from pumping tests is representative of the real boundary conditions, it will be valid for Eq. (1) only if the horizontal deformation is constrained and the deformation is indeed purely vertical. Otherwise, a correction should be introduced to take into account only the contribution of the vertical deformation to the compressibility coefficient (Pujades et al., 2014a):

$\alpha^{\prime}=\alpha \cdot \frac{1+v}{3 \cdot(1-v)}$

which, according to Eq. (3), can be expressed in terms of the storage coefficient as follows:

$S^{\prime}=S \cdot \frac{1+v}{3 \cdot(1-v)}$

where $v$ is the the Poisson's ratio. Observe that the correction reduces the storage coefficient and, therefore, the estimated settlement.

In the case of Glòries Square, since there are some changes in the deformability and transmissivity of the terrain around the construction site, it is reasonable to think that it is a mixed case in which the horizontal deformation might be partially constrained: the Quaternary colluvial deposits on the west side of Glòries Square are stiffer than the Quaternary deltaic deposits on the east side, as well as the Pliocene sands on the northwest side of the tunnel are stiffer than the Pliocene marls on the southeast side. Therefore, the settlement was analytically estimated both with and without the correction, thus giving a range of expectable values.

Nevertheless, some other factors may still lead to the settlement being overestimated:

- In the interpretation of the pumping tests, the water flow is considered to be purely radial. This hypothesis neglects eventual vertical recharge flows from the unsaturated zone, from the saturated but not pumped zone, or from over- or underlying aquitards. If such recharge flows exist, the storage coefficient will be overestimated. In the case of Glòries Square, the wells are screened all along their lengths, so the ground is drained from the surface to the bottom of the wells, and the piezometric data do not show any upward recharge flow.
- Eq. (1) estimates the final settlement once a steady state is reached, as seems to be the case in Glòries Square according to the time series of the water head and deformation. This point is particularly relevant for fine-grained units, which usually concentrate most of the total deformation but take longer to reach a new equilibrium.

- In excavations, the unloading of the terrain due to the removal of material causes uplift of the ground surface, which compensates (part of) the settlement due to the drawdown. This might be valid for the profiles along the tunnel but not for the whole observed area.

One last consideration regarding Eq. (1) is worth mentioning: this formula is valid for overconsolidated aquifers that behave elastically, that is, valid as long as the effective stress (or, equivalently, the drawdown) does not exceed the maximum stress experienced by the aquifer. This is the case of Barcelona. Like many cities with an industrial history, the development of industry in the mid-19th century came with an increasing demand for water. The lack of a sufficient water supply and the availability of sufficient high-quality fresh water from the highly transmissive deltaic aquifers of the Llobregat and Besòs Rivers led to intensive exploitation of these aquifers. Global abstraction reached a maximum of $60-70 \mathrm{Mm}^{3}$ per year by the early 1970 s, which entailed generalised drawdowns of approximately $15 \mathrm{~m}$ (the largest drawdown induced during the current construction works in Glòries Square is $20 \mathrm{~m}$, as shown in Fig. 12). Years later, the contamination of the aquifers and the urbanistic pressure of a growing city motivated a progressive relocation of the industry out of Barcelona, after which the piezometric levels started to recover. By the early 2000s, the aquifers had reached levels similar to those prior to industrialisation (Vàzquez-Suñé et al., 1997; Vàzquez-Suñé et al., 2005). Indeed, the reversibility of deformation has been observed in this case (Fig. 9), as well as in Pujades et al., 2014a, where the ground deformation at three sites close to Glòries Square was analysed.

With all these considerations in mind, the proposed procedure was applied to the case of Glòries Square. With the numerical model and field tests, the storage coefficient was estimated to be approximately $3.3 \cdot 10^{-4}$ for the Quaternary colluvial materials, $3.8 \cdot 10^{-4}$ for the deltaic Quaternary deposits, $5 \cdot 10^{-4}$ for the Pliocene marls and $4 \cdot 10^{-4}$ for the Pliocene sands. The anthropic fill can be ignored since the water table has always remained underneath (Fig. 12). An average value of 0.35 was used for Poisson's ratio, as obtained from Pujades et al., 2014a. In addition, the drawdowns originated from field measurements. With these data, the estimated settlement ranges from -0.5 to $-6 \mathrm{~mm}$ without the correction and from -0.4 to $-4.2 \mathrm{~mm}$ with the correction (Fig. 12).

The analytical results, both with and without the correction taking into account eventual constraints on the horizontal deformation, are in between the D-InSAR and levelling measurements (Fig. 11). Therefore, taking into account the small magnitude of settlement and the lack of levelling data in the excavation area (which is not only a disadvantage with respect to D-InSAR but also an important limitation on this comparison), both the D-InSAR and levelling results can be considered realistic and possible. However, with all due caution, there are still two considerations that would support the levelling results: first, the analytical estimation is more likely to overestimate than to underestimate the magnitude of settlement (because of the previously explained reasons); second, levelling measures values similar to those detected in comparable cases nearby (Pujades et al., 2014a, for instance).

\subsection{General discussion}

The spatial distribution of ground deformation described with DInSAR data (Fig. 6) has linked the settlement with some specific geological units (Fig. 2): the upper aquitard of the Besòs River delta at district scale and the Pliocene marls at construction site scale. In other words, D-InSAR data have allowed the origin of the deformation to be identified. Similarly (albeit at a larger scale and with much more settlement), the D-InSAR results in Tomás et al., 2005, provided key 

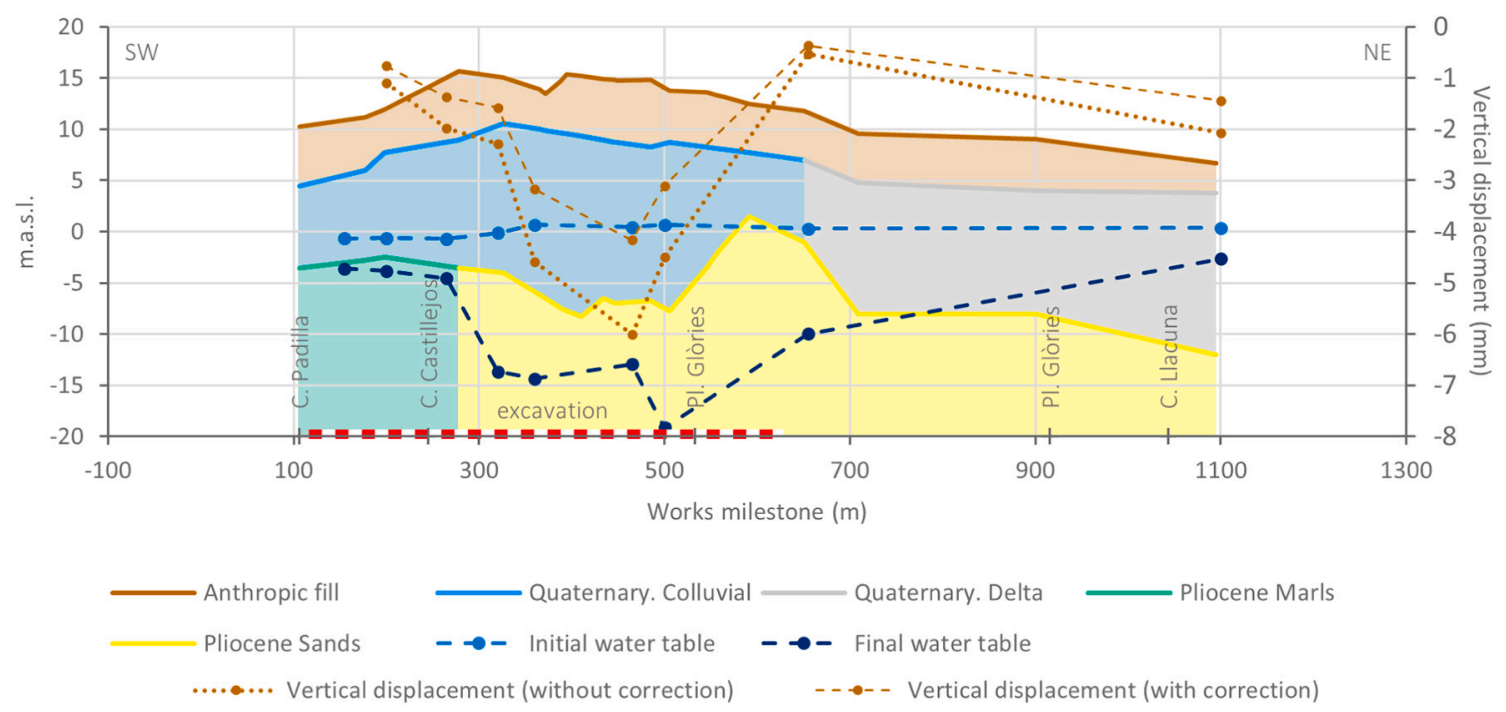

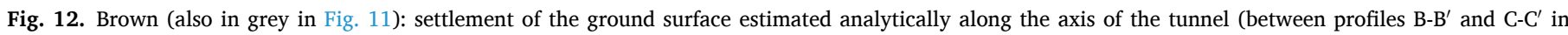

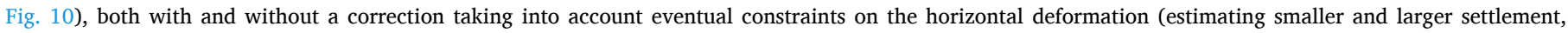

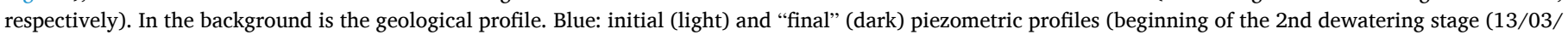
2018) and end of the study period (06/08/2018), respectively).

insights relating the ground subsidence observed in Murcia, Spain, to the compaction of the most recent and unconsolidated sediments of the Segura River caused by overexploitation of the alluvial aquifer. Logically, the insights provided by D-InSAR data in this regard are limited because of its surficial and 2D nature; nevertheless, this technique is precious if these deformation phenomena are to be further studied in depth, as D-InSAR data allow the best locations for better monitoring instruments such as extensometers (as used, for example, in Amelung et al., 1999; Hoffmann et al., 2003; Tomás et al., 2005) to be identified.

Additionally, the D-InSAR data in Glòries Square have revealed the role of some geological features as limits to the spread of ground surface deformation: at the district scale, the contact between the Barcelona Plain and the Besòs River delta for the Quaternary deposits constrains the settlement in the east quadrant; at the construction site scale, the fault between the marls and the sands in the Pliocene materials constrains the settlement on the southeast ("sea") side of the construction. Similar observations can be found in Galloway and Hoffmann, 2007 and Lu and Danskin, 2001 in some case studies in California and Nevada, USA, but again, these studies were conducted at the regional scale and investigated much larger deformation. Note that the geographical scale of analysis is relevant when describing the mechanics of ground deformation phenomena since different elements might come into play. Note also that the larger the deformation is, the clearer these observations. The identification of this kind of geological feature requires spatially dense data over a large area, which cannot be provided by point-like techniques such as levelling and GNSS or any other ground-based technique such as GB-SAR.

Regarding the quantification of deformation, i.e., the accuracy and precision of the results, in the case of Glories Square, the comparison between the D-InSAR and levelling data along the tunnel under construction (Fig. 11) shows a difference in the maximum settlement of between 1 and $6 \mathrm{~mm}$ ( 3 and $18 \mathrm{~mm}$ /year) for D-InSAR values reaching up to $-7 \mathrm{~mm}(-21 \mathrm{~mm} /$ year), with the D-InSAR results being larger. However, neither the magnitude of this difference nor the fact that the D-InSAR results are larger than the levelling measurements can be extrapolated to a general case. For instance, Jiang and Lin, 2010 compared the deformation rates of D-InSAR and levelling results on the subsidence observed at the Hong Kong International Airport, i.e., at a scale more similar to Glòries Square than to the studies mentioned previously in this section. Mean differences of 1.3 and $1.1 \mathrm{~mm} /$ year with a dispersion of 1.6 and $2.1 \mathrm{~mm} /$ year, respectively, were observed for two different D-InSAR datasets for settlement reaching up to $-10 \mathrm{~mm} /$ year, according to the D-InSAR results. In another example, Karila et al., 2013 specifically analysed the D-InSAR performance at measuring ground deformation and presented a comparison with levelling at the building scale. Comparing the mean rates of these two techniques for each of the subsiding buildings analysed in Turku, Finland, they found an average difference of only $0.03 \mathrm{~mm}$ /year for D-InSAR rates up to -9 $\mathrm{mm}$ /year, with the D-InSAR rates in this case being smaller than the levelling rates. Logically, at the point level, i.e., without aggregating or clustering the data measured in the same building, they found larger differences that reflect the challenge of working at such local scales. Finally, when comparing the D-InSAR rates on buildings with groundfixed levelling bases, the differences grew up to $1 \mathrm{~mm} /$ year, thereby showing the relevance of the physical support of the measured points and their mechanical bond with the surroundings, as pointed out at the beginning of the previous section. Similar work was performed by Serrano-Juan et al., 2017, the only study among the abovementioned investigations based on X-band SAR data and not the C-band. They studied the settlement related to the dewatering of a construction site in Barcelona, for which the differences between D-InSAR and levelling reached 3 to $9 \mathrm{~mm}$ ( 2 to $6 \mathrm{~mm} /$ year) for D-InSAR values up to $-8 \mathrm{~mm}$ ( $-5 \mathrm{~mm}$ /year). In addition to working with X-band SAR data, their study revealed another interesting aspect relevant to the purpose of this paper: an analysis of the discrepancy between D-InSAR and levelling concluded that D-InSAR was more accurate since levelling measured only part of the ground deformation due to the locations of some of its reference points within the deforming area -which was detected due to the DInSAR observations. Such a limitation could also be avoided with a differential global positioning system (DGPS), which can still reach a precision on the scale of millimetres (Burbey et al., 2006; Cabral-Cano et al., 2008; Del Soldato et al., 2018). Note that, in the case of Glòries Square, although there is insufficient information to make a clear conclusion, levelling seems to be more accurate than D-InSAR. In brief, the precision and accuracy of D-InSAR remain open issues, but in any case, they are sufficiently high to be valuable when quantifying deformation.

Finally, the time series provided by D-InSAR data (Fig. 9) show that the ground deformation in Glories Square is reversible: the settlement produced during the first dewatering stage (from January until May 2017) fully recovered before the second stage began in March 2018. This aspect is relevant, for example, when modelling the mechanical 
behaviour of soil, as seen in the analytical estimation of the settlement (Eq. 1). In this case, where information would be necessary before instruments were deployed to monitor the phenomena of interest, the capacity of D-InSAR to perform retrospective studies owing to the existence of a historic archive is of great value. In this regard, a similar case can be found in Tomás et al., 2005, where D-InSAR data allowed an analysis of the subsidence in Murcia, Spain, from its onset, i.e., before the overexploitation of the underlying aquifers -the cause of the deformation- began. In contrast, levelling data were available only once damage in several buildings had already been observed.

\section{Conclusions}

The case study presented in this paper has illustrated how D-InSAR data may be valuable in identifying the origin and controlling factors of ground surface deformation, in this case related to the dewatering of construction civil works in an urban environment. Indeed, the continuous spatial description of the deformation and the large extent of the monitored area have linked the observed displacements with specific geological units and have revealed the role played by certain lithological changes in limiting the spread of ground deformation. These features of D-InSAR data have also demonstrated the influence of third-party pumpings nearby. However, the D-InSAR time series clearly show that dewatering controls the evolution of ground deformation. Moreover, the existence of a historical archive of satellite SAR data has made it possible to reconstruct this evolution from before the beginning of the construction works and thus to observe that -in this case- the ground deformation follows the evolution of the water heads during both drawdown and recovery, reflecting the elastic behaviour of the ground. Such observations at the construction site and district scales and with sub-centimetric deformation are beyond the reach of point-like techniques such as levelling. Nevertheless, in general, levelling remains a more accurate and reliable technique in regard to measuring the magnitude of ground deformation.

In summary, levelling usually provides accurate and precise measurements of ground deformation, which remains an open matter for DInSAR, while D-InSAR data provide a much more complete view and understanding of the observed phenomena, demonstrating the complementarity of their strengths and encouraging the integrated use of both techniques.

\section{Author contributions}

Joan Botey i Bassols: Conceptualization, Methodology, Validation, Formal Analysis, Investigation, Writing - Original Draft, Visualization.

Enric Vàzquez-Suñé: Conceptualization, Validation, Investigation, Resources, Writing - Review \& Editing, Supervision, Funding Acquisition.

Michele Crosetto: Validation, Resources, Writing - Review \& Editing, Supervision, Funding Acquisition.

Anna Barra: Resources.

Pierre Gerard: Writing - Review \& Editing, Supervision.

\section{Declaration of Competing Interest}

The authors declare that they have no known competing financial interests or personal relationships that could have appeared to influence the work reported in this paper.

\section{Acknowledgements}

The authors declare the following financial interests/personal relationships which may be considered as potential competing interests: Barcelona d'Infraestructures Municipals S.A. (BIMSA, Ajuntament de Barcelona), as promoter of the construction works in Glòries Square, funded the works of IDAEA-CSIC and CTTC in technical assistance for the Construction Management office. TYPSA (Técnica Y Proyectos S.A.) and Tec-4 (Tec-Cuatro S.A.), as responsible companies for the Construction Management, provided information and data from the works (geometries, operations, monitoring data, etc.). The authors would like to specifically thank the collaboration of Àngel López Arilla (BIMSA), Josep Torrentallé (BIMSA), Laura Baró López (TYPSA), Marc Esquius Berengueras (ESTEYCO S.A.) and Raúl Sánchez Rodríguez (Euro Geotecnica S.A.). This work has been also partially funded by the Spanish Ministry of Economy and Competitiveness through the DEMOS project "Deformation monitoring using Sentinel-1 data" (Ref: CGL2017-83704P); by the European Commission, the Spanish Foundation for Science \& Technology (FECYT) and State Research Agency (AEI) in the frame of the collaborative international consortium URBANWAT (PCI2019103616) financed under the Water JPI Joint Call 2018 of the WaterWorks 2017 ERA-NET Cofund; and by the Spanish Ministry of Science, Innovation and Universities through (1) the project UNBIASED (Ref: RTI 2018-097346-B-I00) under the 2018 call of the "Proyectos de I + D Retos Investigación“; and (2) Project CEX2018-000794-S, IDAEA-CSIC, Centre of Excellence Severo Ochoa. The authors would also like to thank the assistance of Dr. Nieves Lantada Zarzosa (Universitat Politècnica de Catalunya, UPC) and Dr. Estanislao Pujades Garnes (Helmholtz Centre for Environmental Research - UFZ).

\section{References}

Amelung, F., Galloway, D.L., Bell, J.W., Zebker, H.A., Laczniak, R.J., 1999. Sensing the ups and downs of Las Vegas: InSAR reveals structural control of land subsidence and aquifer-system deformation. Geology 27, 483-486. https://doi.org/10.1130/00917613(1999)027<0483:stuado > 2.3.co;2.

Bansal, N., Mukherjee, M., Gairola, A., 2013. Urban Risk Management. International Conference on Challenges in Disaster Mitigation and Management. Indian Institute of Technology Roorkee.

Burbey, T.J., Warner, S.M., Blewitt, G., Bell, J.W., Hill, E., 2006. Three-dimensional deformation and strain induced by municipal pumping, part 1: Analysis of field data. J. Hydrol. 319, 123-142. https://doi.org/10.1016/j.jhydrol.2005.06.028.

Cabral-Cano, E., Dixon, T.H., Miralles-Wilhelm, F., Díaz-Molina, O., Sánchez-Zamora, O., Carande, R.E., 2008. Space geodetic imaging of rapid ground subsidence in Mexico City. Geol. Soc. Am. Bull. 120, 1556-1566. https://doi.org/10.1130/b26001.1.

Carnec, C., Delacourt, C., 2000. Three years of mining subsidence monitored by SAR interferometry, near Gardanne, France. J. Appl. Geophys. 43, 43-54. https://doi. org/10.1016/s0926-9851(99)00032-4.

Cashman, P.M., Preene, M., 2001. Groundwater Lowering in Construction: A Practical Guide. CRC Press.

Cheng, W.C., Li, G., Liu, N.N., Xu, J., Horpibulsuk, S., 2020. Recent massive incidents for subway construction in soft alluvial deposits of Taiwan: a review. Tunn. Undergr. Space Technol. 96, 18. https://doi.org/10.1016/j.tust.2019.103178.

Clarke, J.A., Laefer, D.F., 2014. Evaluation of risk assessment procedures for buildings adjacent to tunnelling works. Tunn. Undergr. Space Technol. 40, 333-342. https:// doi.org/10.1016/j.tust.2013.10.014.

Corominas, J., van Westen, C., Frattini, P., Cascini, L., Malet, J.P., Fotopoulou, S., Catani, F., Van Den Eeckhaut, M., Mavrouli, O., Agliardi, F., Pitilakis, K., Winter, M. G., Pastor, M., Ferlisi, S., Tofani, V., Hervas, J., Smith, J.T., 2014. Recommendations for the quantitative analysis of landslide risk. Bull. Eng. Geol. Environ. 73, 209-263. https://doi.org/10.1007/s10064-013-0538-8.

Crosetto, M., Monserrat, O., Cuevas-González, M., Devanthéry, N., Crippa, B., 2016. Persistent Scatterer Interferometry: a review. ISPRS J. Photogramm. Remote Sens. 115, 78-89. https://doi.org/10.1016/j.isprsjprs.2015.10.011.

Crosetto, M., Devanthéry, N., Monserrat, O., Barra, A., Cuevas-González, M., Mroz, M., Botey-Bassols, J., Vàzquez-Suñé, E., Crippa, B., 2018. A persistent scatterer interferometry procedure based on stable areas to filter the atmospheric component. Remote Sens. 10, 13. https://doi.org/10.3390/rs10111780.

Dassargues, A., 1995. Vers une meilleure fiabilité dans le calcul des tassements dus aux pompages d'eau souterraine. In: Première partie: prise en compte de la variation au cours du temps des paramètres hydrogéologiques et géotechniques, pp. 95-115.

Del Soldato, M., Farolfi, G., Rosi, A., Raspini, F., Casagli, N., 2018. Subsidence Evolution of the Firenze-Prato-Pistoia Plain (Central Italy) Combining PSI and GNSS Data. Remote Sens. 10, 19. https://doi.org/10.3390/rs10071146.

Devanthéry, N., Crosetto, M., Monserrat, O., Cuevas-González, M., Crippa, B., 2014. An Approach to Persistent Scatterer Interferometry. Remote Sens. 6, 6662-6679. https://doi.org/10.3390/rs6076662.

Duranton, G., Puga, D., 2014. The growth of cities. Handbook Econ. Growth 781-853.

Eddies, R., Wood, R., Haynes, A., Warburton, D., Pressdee, C., 2020. Screening ground risk in underground works as part of a predictive modelling approach. In: Proceedings of the Institution of Civil Engineers-Civil Engineering, 173, pp. 49-57. https://doi.org/10.1680/jcien.19.00035.

Ferris, J.G., Knowles, D.B., Brown, R.H., Stallman, R.W., 1962. Theory of Aquifer Tests (Geological Survey). 
Flower, B., Fortnam, M., Kol, L., Sasin, P., Wood, R.G., 2018. Using participatory methods to uncover interacting urban risks: a case study of three informal settlements in Phnom Penh, Cambodia. Environ. Urban. 30, 301-316. https://doi. org/10.1177/0956247817735481.

Font-Capó, J., Vàzquez-Suñé, E., Carrera, J., Martí, D., Carbonell, R., Pérez-Estaun, A., 2011. Groundwater inflow prediction in urban tunneling with a tunnel boring machine (TBM). Eng. Geol. 121, 46-54. https://doi.org/10.1016/j. enggeo.2011.04.012.

Font-Capó, J., Pujades, E., Vàzquez-Suñé, E., Carrera, J., Velasco, V., Montfort, D., 2015 Assessment of the barrier effect caused by underground constructions on porous aquifers with low hydraulic gradient: a case study of the metro construction in Barcelona, Spain. Eng. Geol. 196, 238-250. https://doi.org/10.1016/j. enggeo.2015.07.006.

Galloway, D.L., Burbey, T.J., 2011. Review: Regional land subsidence accompanying groundwater extraction. Hydrogeol. J. 19, 1459-1486. https://doi.org/10.1007/ s10040-011-0775-5.

Galloway, D.L., Hoffmann, J., 2007. The application of satellite differential SAR interferometry-derived ground displacements in hydrogeology. Hydrogeol. J. 15, 133-154. https://doi.org/10.1007/s10040-006-0121-5.

Haack, A., 2010. Construction of the North-South-Metro Line in Cologne and the accident on March 3rd, 2009. In: Transport and City Tunnels - Proceedings of the 11th International Conference Underground Constructions Prague 2010, pp. 14-18.

Herce Vallejo, M., Magrinyà Torner, F., 2002. La ingeniería en la evolución de la urbanística. Edicions UPC. http://hdl.handle.net/2099.3/36703.

Hoffmann, J., Galloway, D.L., Zebker, H.A., 2003. Inverse modeling of interbed storage parameters using land subsidence observations, Antelope Valley, California. Water Resour. Res. 39, 13. https://doi.org/10.1029/2001wr001252.

IDAEA-CSIC, 2015. Nota tècnica: Construcció del model hidrogeològic. Interpretació de la prova de bombament (agost-setembre de 2015). Novembre 2015. In: Technical Report, p. 59.

IDAEA-CSIC, 2016. Nota tècnica: Validació disseny del sistema d'esgotament del freàtic per les obres dels túnels viaris a les Glòries (Barcelona). Octubre 2016. In: Technical Report, p. 19.

Jacob, C.E., 1950. Flow of ground water. In: Rouse, H. (Ed.), Engineering Hydraulics. John Wiley, New York, pp. 321-386.

Jiang, L.M., Lin, H., 2010. Integrated analysis of SAR interferometric and geological data for investigating long-term reclamation settlement of Chek Lap Kok Airport, Hong Kong. Eng. Geol. 110, 77-92. https://doi.org/10.1016/j.enggeo.2009.11.005.

Jurado, A., Mastroianni, N., Vàzquez-Suñé, E., Carrera, J., Tubau, I., Pujades, E., Postigo, C., de Alda, M.L., Barcelo, D., 2012. Drugs of abuse in urban groundwater. A case study: Barcelona. Sci. Total Environ. 424, 280-288. https://doi.org/10.1016/j. scitotenv.2012.02.074.

Karila, K., Karjalainen, M., Hyyppa, J., Koskinen, J., Saaranen, V., Rouhiainen, P., 2013. A Comparison of Precise Leveling and Persistent Scatterer SAR Interferometry for Building Subsidence Rate Measurement. ISPRS Int. J. Geo Inf. 2, 797-816. https:// doi.org/10.3390/ijgi2030797.

Lu, Z., Danskin, W.R., 2001. InSAR analysis of natural recharge to define structure of a ground-water basin, San Bernardino, California. Geophys. Res. Lett. 28, 2661-2664. https://doi.org/10.1029/2000g1012753.

Mahmoudpour, M., Khamehchiyan, M., Nikudel, M.R., Ghassemi, M.R., 2016. Numerical simulation and prediction of regional land subsidence caused by groundwater exploitation in the southwest plain of Tehran, Iran. Eng. Geol. 201, 6-28. https:// doi.org/10.1016/j.enggeo.2015.12.004.

Motagh, M., Shamshiri, R., Haghighi, M.H., Wetzel, H.U., Akbari, B., Nahavandchi, H., Roessner, S., Arabi, S., 2017. Quantifying groundwater exploitation induced subsidence in the Rafsanjan plain, southeastern Iran, using InSAR time-series and in situ measurements. Eng. Geol. 218, 134-151. https://doi.org/10.1016/j. enggeo.2017.01.011.

Perski, Z., Hanssen, R., Wojcik, A., Wojciechowski, T., 2009. InSAR analyses of terrain deformation near the Wieliczka Salt Mine, Poland. Eng. Geol. 106, 58-67. https:// doi.org/10.1016/j.enggeo.2009.02.014.
Pujades, E., Carrera, J., Vàzquez-Suñé, E., Jurado, A., Vilarrasa, V., MascunanoSalvador, E., 2012. Hydraulic characterization of diaphragm walls for cut and cover tunnelling. Eng. Geol. 125, 1-10. https://doi.org/10.1016/j.enggeo.2011.10.012.

Pujades, E., Vàzquez-Suñé, E., Carrera, J., Jurado, A., 2014a. Dewatering of a deep excavation undertaken in a layered soil. Eng. Geol. 178, 15-27. https://doi.org/ 10.1016/j.enggeo.2014.06.007.

Pujades, E., Vàzquez-Suñé, E., Carrera, J., Vilarrasa, V., De Simone, S., Jurado, A., Ledesma, A., Ramos, G., Lloret, A., 2014b. Deep enclosures versus pumping to reduce settlements during shaft excavations. Eng. Geol. 169, 100-111. https://doi. org/10.1016/j.enggeo.2013.11.017.

Pujades, E., Vàzquez-Suñé, E., Culi, L., Carrera, J., Ledesma, A., Jurado, A., 2015 Hydrogeological impact assessment by tunnelling at sites of high sensitivity. Eng. Geol. 193, 421-434. https://doi.org/10.1016/j.enggeo.2015.05.018.

Pujades, E., Jurado, A., Carrera, J., Vàzquez-Suñé, E., Dassargues, A., 2016. Hydrogeological assessment of non-linear underground enclosures. Eng. Geol. 207, 91-102. https://doi.org/10.1016/j.enggeo.2016.04.012.

Pujades, E., De Simone, S., Carrera, J., Vàzquez-Suñé, E., Jurado, A., 2017. Settlements around pumping wells: Analysis of influential factors and a simple calculation procedure. J. Hydrol. 548, 225-236. https://doi.org/10.1016/j. jhydrol.2017.02.040.

Rosen, P.A., Hensley, S., Joughin, I.R., Li, F.K., Madsen, S.N., Rodriguez, E., Goldstein, R. M., 2000. Synthetic aperture radar interferometry - Invited paper. Proc. IEEE 88 , 333-382. https://doi.org/10.1109/5.838084.

Serrano-Juan, A., Pujades, E., Vàzquez-Suñé, E., Crosetto, M., Cuevas-González, M., 2017. Leveling vs. InSAR in urban underground construction monitoring: pros and cons. Case of la sagrera railway station (Barcelona, Spain). Eng. Geol. 218, 1-11. https://doi.org/10.1016/j.enggeo.2016.12.016.

Svalova, V., 2018. Risk analysis and land use planning. In: Jorge Rocha, J.A.T. (Ed.), Spatial Analysis Modelling and Planning. IntechOpen.

Tomás, R., Márquez, Y., López-Sánchez, J.M., Delgado, J., Blanco, P., Mallorquí, J.J., Martínez, M., Herrera, G., Mulas, J., 2005. Mapping ground subsidence induced by aquifer overexploitation using advanced Differential SAR Interferometry: Vega Media of the Segura River (SE Spain) case study. Remote Sens. Environ. 98, 269-283. https://doi.org/10.1016/j.rse.2005.08.003.

Vàzquez-Suñé, E., Sánchez-Vila, X., Carrera, J., Marizza, M., Arandes, R., Gutiérrez, L.A., 1997. Rising groundwater levels in Barcelona: evolution and effects on urban structures. In: Groundwater in the Urban Environment - Vol I: Problems, Processes and Management, pp. 267-271.

Vàzquez-Suñé, E., Sánchez-Vila, X., Carrera, J., 2005. Introductory review of specific factors influencing urban groundwater, an emerging branch of hydrogeology, with reference to Barcelona, Spain. Hydrogeol. J. 13, 522-533. https://doi.org/10.1007/ s10040-004-0360-2.

Vàzquez-Suñé, E., Carrera, J., Tubau, I., Sánchez-Vila, X., Soler, A., 2010. An approach to identify urban groundwater recharge. Hydrol. Earth Syst. Sci. 2085-2097. https:// doi.org/10.5194/hess-14-2085-2010.

Vàzquez-Suñé, E., Marazuela, M.A., Velasco, V., Diviu, M., Pérez-Estaun, A., ÁlvarezMarrón, J., 2016. A geological model for the management of subsurface data in the urban environment of Barcelona and surrounding area. Solid Earth 7, 1317-1329. https://doi.org/10.5194/se-7-1317-2016.

Velasco, V., Cabello, P., Vàzquez-Suñé, E., López-Blanco, M., Ramos, E., Tubau, I., 2012. A sequence stratigraphic based geological model for constraining hydrogeological modeling in the urbanized area of the Quaternary Besòs delta (NW Mediterranean coast, Spain). Geol. Acta 373-393. https://doi.org/10.1344/105.000001757.

Wasowski, J., Bovenga, F., 2014. Investigating landslides and unstable slopes with satellite Multi Temporal Interferometry: current issues and future perspectives. Eng. Geol. 174, 103-138. https://doi.org/10.1016/j.enggeo.2014.03.003.

Yerro, A., Corominas, J., Monells, D., Mallorqui, J.J., 2014. Analysis of the evolution of ground movements in a low densely urban area by means of DInSAR technique. Eng. Geol. 170, 52-65. https://doi.org/10.1016/j.enggeo.2013.12.002. 